\title{
Door Security Design using Radio Frequency Identification With a Short Message Service Warning System
}

\author{
Hartati Deviana, M. Miftakul Amin, Roy Sandy, Phong Thanh Nguyen, Wahidah Hashim, Andino \\ Maseleno
}

\begin{abstract}
In the workspace, when we are working at home it is vital for property holders to keep up vital records and information. In this manner, the security of the workspace entryway is extremely important to build security and it can avoid burglary when the workspace isn't utilized or relinquished. The easiest security for the entryway is introducing a manual key. Yet, manual key is anything but difficult to break. With advancement of entryway security innovation it utilizes watchword, finger check, and numerous others, yet security is just to open and shutting entryway. Yet, when the entryway was persuasively opened or harmed by hoodlums, the property holder still had no data that the entryway was broken. To conquer this issue, a framework that can supplant the manual entryway bolt to a more advanced entryway security framework is required with the goal that it is difficult to separate and can see whether the entryway is opened or harmed by a cheat. To run this framework, 3 parts are utilized, to be specific RFID card as a key re-arrangement apparatus, a sensor to gauge vibration on the entryway when it is constrained open or harmed by criminals and tells the mortgage holder by means of SMS.
\end{abstract}

Index Terms: Door security, radio frequency, short message service

\section{INTRODUCTION}

\subsection{Background}

The development of science and technology in the world is increasing rapidly now, it can be seen from the number of technology-based electronics that can facilitate human work, one of which is a microcontroller. Currently microcontroller is widely used to control a device.

Current technological developments must be able to meet the increasing needs and demands of users in the ease and speed of data processing [1]. Even now it is demanded the ability of the system to exchange data and information [2]. In the workspace, when we are working at home it is very important for homeowners to maintain important files and

Revised Manuscript Received on June 22, 2019.

Hartati Deviana, Politeknik Negeri Sriwijaya, Palembang, Indonesia

M. Miftakul Amin, Politeknik Negeri Sriwijaya, Palembang, Indonesia Roy Sandy, Politeknik Negeri Sriwijaya, Palembang, Indonesia

Phong Thanh Nguyen, Department of Project Management, Ho Chi Minh City Open University (HCMCOU), Vietnam.

Wahidah Hashim, Institute of Informatics and Computing Energy, Universiti Tenaga Nasional, Malaysia

Andino Maseleno, Institute of Informatics and Computing Energy, Universiti Tenaga Nasional, Malaysia data. Therefore, the security of the workspace door is very necessary to increase security and it can prevent theft when the workspace is not used or abandoned. Security systems play an important role to prevent unknown user entry into secured place [3]. Security can also be seen as a condition so that one can develop and progress freely [4].

The simplest security for the door is installing a manual key. But manual key is very easy to break. With development of door security technology it uses password, finger scan, and many others, but security is only for opening and closing door. But when the door was forcibly opened or damaged by thieves, the homeowner still had no information that the door was broken.

To overcome this problem, a system that can replace the manual door lock to a more sophisticated door security system is needed so that it is not easy to break down and can find out if the door is opened or damaged by a thief. To run this system, 3 components are used, namely RFID card as a key replacement tool, a sensor to measure vibration on the door when it is forced open or damaged by thieves and notifies the homeowner via SMS. Radio frequency identification (RFID) is a wireless technology that can be used to develop access control system [5].

\subsection{Problem Formulation}

In designing door security system, the problems to be discussed are how to design the manufacture of door safeguards by using Radio Frequency Indication (RFID) and Vibration Sensors and sending notifications to homeowners using SMS.

\subsection{Problem Limitation}

In order to make discussion more directed and not deviating from existing problems, the authors limit the problems in this final report project, among others:

a. Door security is made prototype only

b. Tag RFID which is valid is only one

c. Electricity resources used from PLN

\subsection{Research Purpose}

This research purpose was to create or to design a door that has a security system that uses the Radio Frequency Identification (RFID) tag as a locking medium and a vibration sensor as the door detector is opened forcibly and the notification system uses SMS.

\subsection{Research Benefit}

Therefore the benefits of final report writing are

1. Provide more security to the door, so that the workspace owner feels safe when leaving the room.

2. Notify the workspace owner when the door is opened or damaged by a thief. 


\section{LITERATURE REVIEW}

\section{A. Microcontroller}

Microcontroller (micro controller) in an electronic circuit serves as a controller that regulates working process of electronic circuits. In the IC microcontroller there is a CPU, memory, timer, serial and parallel communication channels, input / output ports, ADC, and others [6].

\section{1) AVR Microcontroller}

AVR has the extension, that is Advanced Versatile RISC or Alf And Vegards Risc processor that comes from two students' name in Norwegian Institute Of Technology (NTH), namely Alf-Egil Boken and Vegard Wollan. In general, AVR microcontroller can be grouped into five groups: Attiny family, AT90Sxx, ATMega, Xmega AVR, and UC3 AVR32 [6].

ATMega328 is a microcontroller output from atmel which has a RISC (Reduction Instruction Set Computer) architecture in which each data execution process is faster than the CISC (Completed Instruction Set Computer) architecture.

This microcontroller has some features among others :

- 130 kinds of instruction that almost be executed in onle clock cycle.

- Multipurpose 32 x 8-bit register.

- The Speed reach to 16 MIPS with $16 \mathrm{MHz}$ clock.

- $32 \mathrm{~KB}$ Flash memory and in Arduino has $2 \mathrm{~KB}$ bootloader from flash memory

- Having 1 KB EEPROM (Electrically Erasable Programmable Read Only Memory) as semipermanent data storage because EEPROM still can store data although power supply is turned off.

- Having 2 KB SRAM (Static Random Access Memory)

- Having pin I/O as many as 14 pins, six of them are PWM (Pulse Width Modulation) outputs.

- Master / Slave SPI Serial interface.

ATmega 328 microcontroller has a Harvard architecture which separates memory for program code and memory for data so that it can maximize work and parallelism. Instructions in program memory are executed in a single path, where when one instruction is done the next instruction has been taken from the program memory. This concept allows instructios to be executed in every clock cycle. Multipurpose $32 \times 8$-bit register is used to support operations on the ALU (Arithmatic Logic unit) which can be done in one cycle. six of this multipurpose register can be used as three pieces of 16-bit pointer registers in indirect addressing mode to retrieve data in the data memory space. These three 16-bit pointer registers are called $\mathrm{X}$ registers (combination of R26 and R27), register Y (combination of $\mathrm{R} 28$ and R29), and register $\mathrm{Z}$ (combination of R30 and R31). Almost all AVR instructions have a 16-bit format. Each program memory address consists of 16-bit or 32-bit instructions.

Beside multipurpose register above, there are other registers that are mapped with $\mathrm{I} / \mathrm{O}$ memory mapped

\section{2) AVR ATMega328 Feature}

technique as wide as 64 bytes. Some of these registers are used for special functions such as Timer / Counter, Interrupt, ADC, USART, SPI, EEPROM, and other I / O registers. These registers occupy memory at the address 0x20h - 0x5Fh. Architecture ATmega 328 display as figure 1.

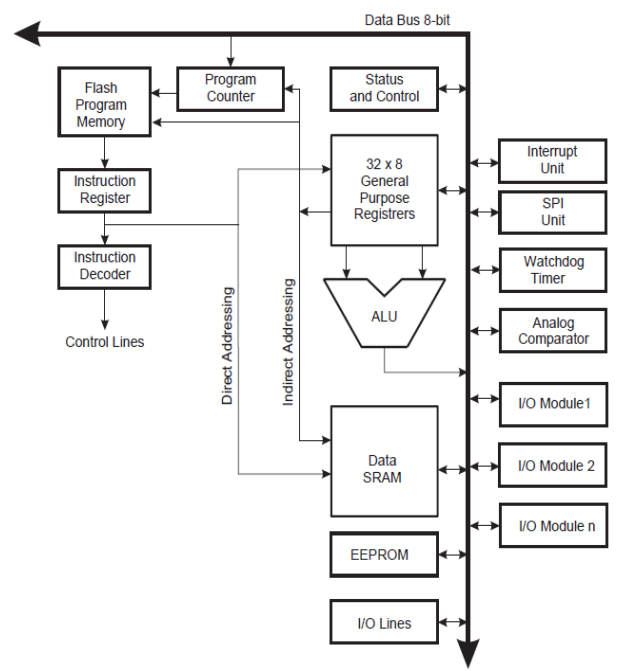

Fig. 1 Architecture ATmega328

3) PIN ATMega328 Configuration

Atmega328 Datasheet display as figure 2.

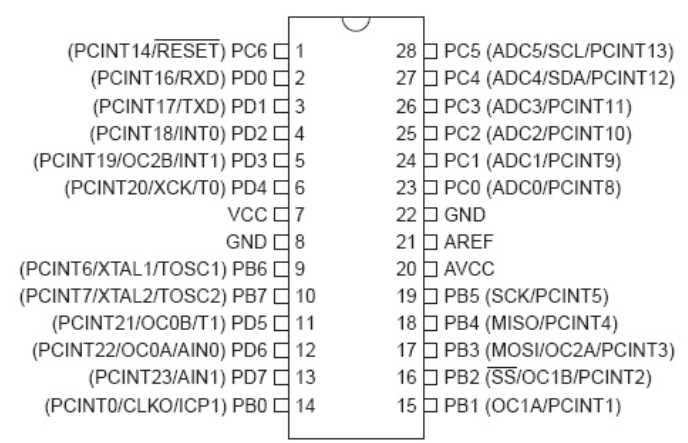

Fig. 2 ATMega328 Configuration PIN Atmega328 microcontroller has a number of 28 pins. Each Atmega328 microcontroller pin has the usage as shown in table 1 , table 2 and table 3 .

Table. 1 Port B Configuration

\begin{tabular}{|c|c|}
\hline Port Pin & Alternate Functions \\
\hline PB7 & $\begin{array}{l}\text { XTAL2 (Chip Clock Oscillator pin 2) } \\
\text { TOSC2 (Timer Oscillator pin 2) } \\
\text { PCINT7 (Pin Change Interrupt 7) }\end{array}$ \\
\hline PB6 & $\begin{array}{l}\text { XTAL1 (Chip Clock Oscillator pin } 1 \text { or External clock input) } \\
\text { TOSC1 (Timer Oscillator pin 1) } \\
\text { PCINT6 (Pin Change Interrupt 6) }\end{array}$ \\
\hline PB5 & $\begin{array}{l}\text { SCK (SPI Bus Master clock Input) } \\
\text { PCINT5 (Pin Change Interrupt 5) }\end{array}$ \\
\hline PB4 & $\begin{array}{l}\text { MISO (SPI Bus Master Input/Slave Output) } \\
\text { PCINT4 (Pin Change Interrupt 4) }\end{array}$ \\
\hline PB3 & $\begin{array}{l}\text { MOSI (SPI Bus Master Output/Slave Input) } \\
\text { OC2A (Timer/Counter2 Output Compare Match A Output) } \\
\text { PCINT3 (Pin Change Interrupt 3) }\end{array}$ \\
\hline PB2 & $\begin{array}{l}\overline{S S} \text { (SPI Bus Master Slave select) } \\
\text { OC1B (Timer/Counter1 Output Compare Match B Output) } \\
\text { PCINT2 (Pin Change Interrupt 2) }\end{array}$ \\
\hline PB1 & $\begin{array}{l}\text { OC1A (Timer/Counter1 Output Compare Match A Output) } \\
\text { PCINT1 (Pin Change Interrupt 1) }\end{array}$ \\
\hline PBO & $\begin{array}{l}\text { ICP1 (Timer/Counter1 Input Capture Input) } \\
\text { CLKO (Divided System Clock Output) } \\
\text { PCINTO (Pin Change Interrupt 0) }\end{array}$ \\
\hline
\end{tabular}

Published By: 
Table. 2 Port C Configuration

\begin{tabular}{|c|l|}
\hline Port Pin & Alternate Function \\
\hline PC6 & $\begin{array}{l}\text { RESET (Reset pin) } \\
\text { PCINT14 (Pin Change Interrupt 14) }\end{array}$ \\
\hline PC5 & $\begin{array}{l}\text { ADC5 (ADC Input Channel 5) } \\
\text { SCL (2-wire Serial Bus Clock Line) } \\
\text { PCINT13 (Pin Change Interrupt 13) }\end{array}$ \\
\hline PC4 & $\begin{array}{l}\text { ADC4 (ADC Input Channel 4) } \\
\text { SDA (2-wire Serial Bus Data Input/Output Line) } \\
\text { PCINT12 (Pin Change Interrupt 12) }\end{array}$ \\
\hline PC3 & $\begin{array}{l}\text { ADC3 (ADC Input Channel 3) } \\
\text { PCINT11 (Pin Change Interrupt 11) }\end{array}$ \\
\hline PC2 & $\begin{array}{l}\text { ADC2 (ADC Input Channel 2) } \\
\text { PCINT10 (Pin Change Interrupt 10) }\end{array}$ \\
\hline PC1 & $\begin{array}{l}\text { ADC1 (ADC Input Channel 1) } \\
\text { PCINT9 (Pin Change Interrupt 9) }\end{array}$ \\
\hline PC0 & $\begin{array}{l}\text { ADC0 (ADC Input Channel 0) } \\
\text { PCINT8 (Pin Change Interrupt 8) }\end{array}$ \\
\hline
\end{tabular}

Table. 3 Port D Configuration

\begin{tabular}{|c|l|}
\hline Port Pin & Alternate Function \\
\hline PD7 & $\begin{array}{l}\text { AIN1 (Analog Comparator Negative Input) } \\
\text { PCINT23 (Pin Change Interrupt 23) }\end{array}$ \\
\hline PD6 & $\begin{array}{l}\text { AIN0 (Analog Comparator Positive Input) } \\
\text { OC0A (Timer/Counter0 Output Compare Match A Output) } \\
\text { PCINT22 (Pin Change Interrupt 22) }\end{array}$ \\
\hline PD5 & $\begin{array}{l}\text { T1 (Timer/Counter 1 External Counter Input) } \\
\text { OC0B (Timer/Counter0 Output Compare Match B Output) } \\
\text { PCINT21 (Pin Change Interrupt 21) }\end{array}$ \\
\hline PD4 & $\begin{array}{l}\text { XCK (USART External Clock Input/Output) } \\
\text { T0 (Timer/Counter 0 External Counter Input) } \\
\text { PCINT20 (Pin Change Interrupt 20) }\end{array}$ \\
\hline PD3 & $\begin{array}{l}\text { INT1 (External Interrupt 1 Input) } \\
\text { OC2B (Time/Counter2 Output Compare Match B Output) } \\
\text { PCINT19 (Pin Change Interrupt 19) }\end{array}$ \\
\hline PD2 & $\begin{array}{l}\text { INT0 (External Interrupt 0 Input) } \\
\text { PCINT18 (Pin Change Interrupt 18) }\end{array}$ \\
\hline PD1 & $\begin{array}{l}\text { TXD (USART Output Pin) } \\
\text { PCINT17 (Pin Change Interrupt 17) }\end{array}$ \\
\hline PD0 & $\begin{array}{l}\text { RXD (USART Input Pin) } \\
\text { PCINT16 (Pin Change Interrupt 16) }\end{array}$ \\
\hline &
\end{tabular}

\subsection{Arduino}

\subsubsection{History of Arduino}

Arduino is open source electronics prototyping platform composed of a microcontroller, a programming language, and IDE [7]. Arduino was developed from Hernando Barragan's thesis in 2004, a student from Colombia. The title of the thesis was "Arduino-Revolution Open Hardware". Arduino began at the Interactive Design Institute class in Ivrea (IDII) class, in 2005, in Ivera, Italy. Arduino was discovered by Massimo Banzi and David Cuartielles with the initial aim of helping students create design tools and interact with low prices compared to other devices available at the time, such as BASIC Stamp which was quite expensive for students at that time. Arduino comes from Italian, which means courageous friend. On May 2011, Arduino had been sold more than 300,000 units. Arduino is now one of the OSHW (Open Source Hadrware) platforms.

\subsubsection{Definition of Arduino}

Arduino is a microcontroller board that is open source, where schematic and PCB design are open source, so we can use or modify, Arduino Board uses the Atmel AVR microcontroller chip, for example: Arduino NG or Older w / Atmega8 (Severino), Arduino Duemilanove or Nano w / Atmega328, Arduino Uno, Arduno Mega2560, etc. Software to create, to compile and to upload program namely Arduino IDE or also called Arduino Software which is also open source. This software can be downloaded at the site http://www.arduino.cc. Arduino IDE (Arduino Software) generates a hex file from the program instruction code line that uses $\mathrm{C}$ language called sketch after compiling with the Verify / Compile command.

The Bootloader Chip / IC on the Arduino Board has been filled in by a program called Arduino bootloader, which allows us to upload program code without using additional hardware (without using external programmers, such as: AVR-ISP, STK500, parallel programmer, usb programmer). The bootloader will be active for a few seconds when the board is reset.

The compilation results from Arduino Software can be used and can be run not only on the Arduino board but also can be run on Avr's microcontroller systems which are even without bootloader. If we don't use the bootloader, it means that the bigger the program that can be inserted into the flash microcontroller memory, because flash memory is only used for our application program, beside that we can avoid the delay when the board has a reset due to run the program on the bootloader. However, to enter program or to burn sketch, we must use external programmers such as: AVR-ISP, STK500, parallel programmer, usb programmer (USBasp).

\subsubsection{Arduino UNO Board}

Arduino Uno board uses ATmega328 microcontroller. In general, the position / location of I / O terminal pins on various Arduino Board positions is the same as the position / position of the Arduino Uno I / O terminal pins which have 14 Digital pins that can be set as Input / Output (some of which have dual functions), 6 pins analog input.

This part will explain the function of pin and terminat on Arduino Uno board. Arduino Uno board can be seen in figure 3.

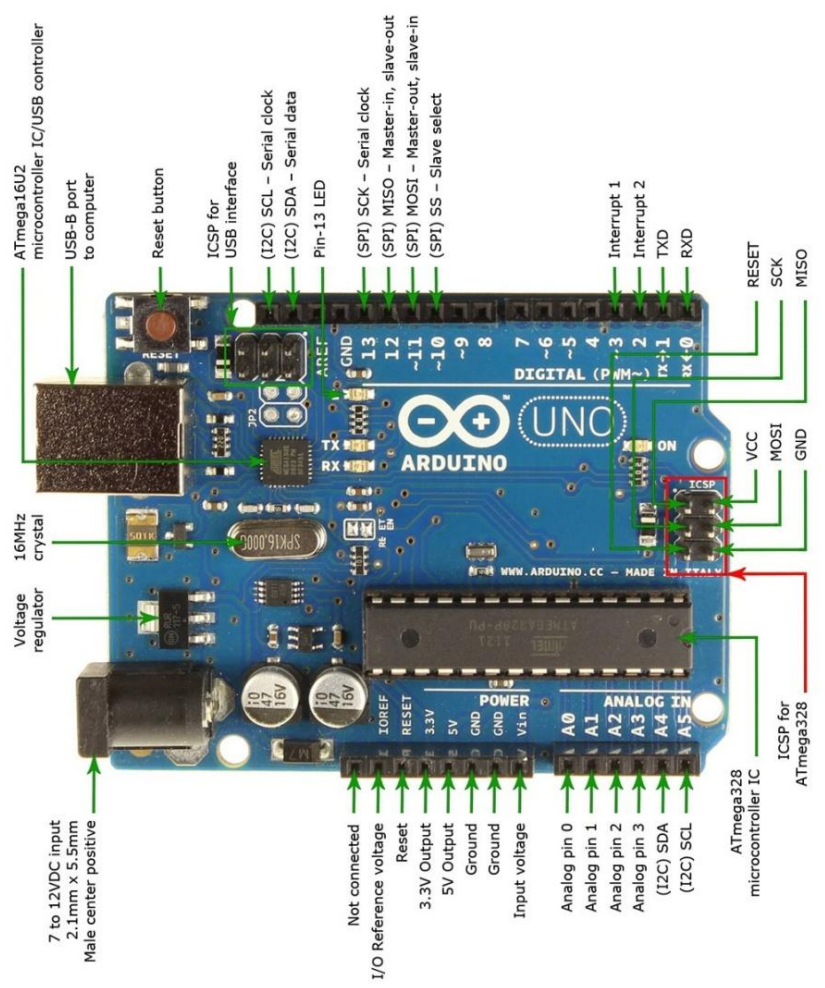

Fig. 3 Arduino UNO Board

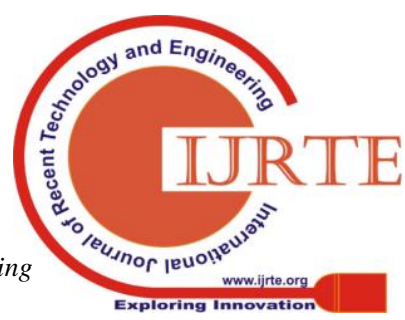




\section{USB to Computer}

It is used to connect to computer or another device using RS-232 serial standart. It works when JP0 is in 2-3 position.

\section{DC1, 2.1mm power jack}

Used as a source of power supply from outside, there is a voltage regulator that can regulate the input voltage between $+7 \mathrm{~V}$ to $+12 \mathrm{~V}$ (input the recommended voltage between $+9 \mathrm{~V}$ to $+12 \mathrm{~V}$ ). Vin and $5 \mathrm{~V}$ pins can be used as sources when given a source of external invoices.

\section{ICSP, 2x3 header pin}

To program the ATmega bootloder or program Arduino with other softwares, the following is a description of the function of each pin in table 4.

Table. 4 Description of ICSP pin at Arduino Uno

\begin{tabular}{lllll}
\cline { 2 - 4 } 1 & MISO & $+5 \mathrm{v}$ & 2 \\
3 & SCK & MOSI & 4 \\
5 & RST & GND & 6
\end{tabular}

\section{JP0, 3 jumper pin}

When 2-3 position, the board is in a serial enable (X1 connector can be used). When 1-2 board position on serial disable (X1 connector does not work) and external pull-down resistor on pin0 $(\mathrm{Rx})$ and pin1 $(\mathrm{Tx})$ are active, pull-down resistor to prevent noise from $\mathrm{Rx}$.

\section{JP4}

When in 1-2 position, the board can activate the auto-reset function, which functions when uploading the program on the board without the need to press the $\mathrm{S} 1$ reset button.

\section{S1}

$\mathrm{S} 1$ is push button which functions as reset button.

\section{LED}

POWER led: Will be on when arduino is turned on by given voltage from DC1.

Rx led: Blink when receiving data through computer via serial communication

Tx led: blink when sending data via serial communication

L led: connected with digital pin13. Blinking when bootloading

\section{DIGITAL PINOUT IN/OUT}

13 digital pin input / output: pin 0-7 (connected to PORT D from ATmega). Pin0 (Rx) and Pin1 (Tx) can be used as communication pin. For Atmega 168/328 pin 3.5 and 6 can be used as PWM outputs. Six (6) digital pin inputs / outputs: pin 8-13 (connected to PORT B). Pin10 (SS), pin11 (MOSI), pin12 (MISO), pin13 (SCK) which can be used as SPI (Serial Peripheral Interface). Pin 9.10, and 11 can be used as PWM output for ATmega 8 and ATmega 168/328.

\section{ANALOG PINOUT INPUT}

Six (6) analog inputs: pin 0-5 (A0-A5) (connected to PORT C). pin4 (SDA) and pin5 (SCL) which can be used as I2C (two-wire serial bus). This analog pin can be used as a digital14 pin (A0) to 19 (A5) pin.

\subsection{Radio Frequency Identification (RFID) \\ 2.3.1 Definition of Radio Frequency Identification (RFID)}

RFID is an effective automatic identification technology for variety of objects, its functionality is ability to track the location of the tagged item [8]. RFID is the process of identifying a person or object using radio transmission frequency. RFID uses radio frequency to read information from a small device called a tag or transponder (Transmitter + Responder). RFID tags will recognize themselves when detecting signals from compatible devices, namely RFID readers.

RFID is an identification technology that is flexible, easy to use, and very suitable for automatic operations. RFID combines advantages that are not available in other identification technologies. RFID can be provided in devices that can only be read (Read Only) or can be read and written (Read / Write), it does not require direct contact or light path to be able to operate, it can function in a variety of environmental conditions, and provide a level of high data integrity . In addition, because this technology is difficult to be fallsified, RFID can provide a high level of security.

In general RFID systems, tags or transponders are attached to an object. Each tag can carry unique information, including: serial number, model, color, assembly place, and other data from the object. When this tag is through a field generated by a compatible RFID reader, the tag will transmit the information contained in the tag to the RFID reader, so that the object identification process can be carried out.

RFID system consists of four components, it can be seen in the following figure:

- Tag: This is a device for storing information for identifying object. RFID tag is often called as transponder.

- Antenna: to transmit radio frequency signal between RFID with tag RFID. RFID reader is compatible device with RFID tag that will communicate with tag in wireless.

- Application software is application for workstation or PC that can read data from tag through RFID reader. Both tag and RFID is completed with antenna for receving and radiating electromagnetic wave

\subsubsection{RFID system}

The following is RFID system as figure 4 


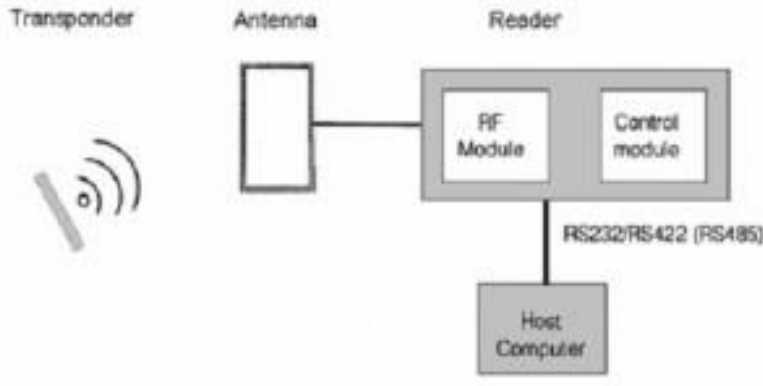

Fig. 4 RFID System

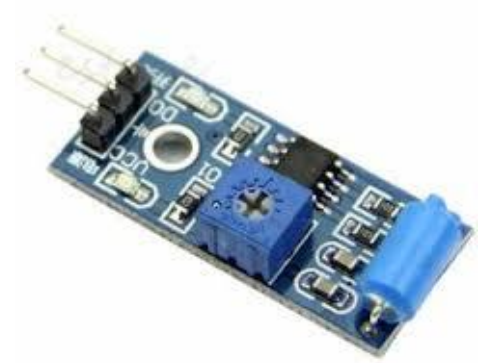

Fig. 5 SW-420 Vibration Sensor

\subsubsection{RFID Reader}

A RFID reader must finish two tasks namely :

Receving command from application software Communicating with RFID tag.

The RFID reader is a link between the application software and the antenna that will radiate radio waves to the RFID tag. The radio waves emitted by the antenna propagate in the surrounding space. As a result, data can move wirelessly to RFID tags that are adjacent to the antenna.

\subsubsection{Tag RFID}

RFID tag is device made from electronic circuits and antenna that are integrated in the circuit. Electronic circuits of RFID tag generally have memory so this tag has the ability to store data. The memory in the tag is divided into cells. Some cells store Read Only data, for example a unique serial number that is stored when the tag is produced. Other cells in RFID may also be written and read repeatedly.

According to power supply tag, RFID tag is grouped become :

- Active Tag is the tag whose power is obtained from the battery, so that it will reduce the power needed by the RFID reader and the tag can send information over a longer distance. The disadvantage of this tag type is its expensive price and larger size because it is more complex. The more functions that RFID tags can do, the more complex the series and the larger the size.

- Passive Tag is the tag whose power supply is obtained from the field produced by RFID reader. The circuit is simpler, the price is cheaper, small in size, and lighter. The disadvantage is that tag can only send information in close proximity and RFID readers must provide additional power for RFID tags.

RFID tag has often been considered for use as barcodes in the future. Reading information on RFID tag does not require contact at all. Because of the capabilities of modern integrated circuit, RFID tag can store more information than barcodes. The plural reading feature on RFID technology is often referred to as anti collision

\subsection{Vibration Sensor}

Vibration sensor is a sensor that can measure the vibration of an object whose data will be processed for experimental purposes or used to anticipate a possible danger. It has measurement accuracy and increasing the sensitivity range [9]. One type of vibration sensor is the SW-420 sensor. Display form of SW-420 vibration sensor like figure 5.

\subsection{Solenoid Door Lock}

Solenoid is a coil of copper wire which is tightly wrapped around an iron core to produce an electromagnet field [10]. The coil is like a figure 6 which is often called a solenoid, this solenoid is a very strong magnetic field in its iron core, assuming that the winding length is greater than the diameter of the cable or copper. Ideally, the solenoid has an infinite twist length with the tightness of the tight cable coinciding with each other. Then it will produce the same electromagnetic field that same one with a parallel constant to the axis iron core.

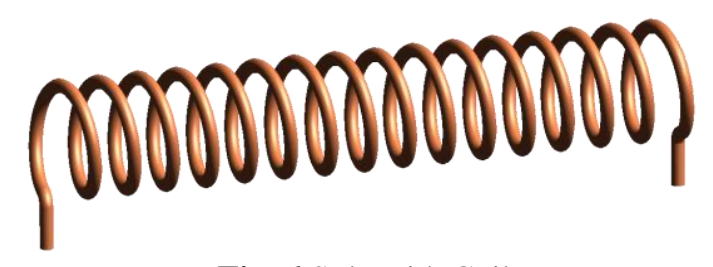

Fig. 6 Solenoid Coil

If we circulate electricity to the iron rod placed in the middle of the windings, the stale rod will get magnetic induction and eventually become a magnet. With the placement of a part of the iron rod, it is inside the solenoid and some of it is on the outside. The magnet-induced iron rod will draw metal objects into the solenoid. This is used to move the lever, close and lock the door, or move the door lock slot. The working principle of DC solenoid is quite similar to an $\mathrm{Ac}$ solenoid, both are specially designed and produce an electromagnetic field.

The round and conical iron core, one end has a positive pole. When the iron core is inserted into the center of the coil full of magnetic fields, the surface of the other end has a negative pole. While at the bottom there is a large enough area to channel the flow of magnetic flux.

\subsection{Transformator ( Trafo)}

Transformer or often abbreviated as Transformer is an electrical device that can change the level of an $\mathrm{AC}$ voltage to another level. The purpose of changing these levels includes reducing AC Voltage from 220VAC to $12 \mathrm{VAC}$ or increasing the Voltage from 110VAC to $220 \mathrm{VAC}$. This transformer or transformer works based on the principle of Electromagnetic Induction and can only work at alternating current (AC) voltage. 
Transformer (Transformer) plays a very important role in the distribution of electric power. The transformer raises electricity from the PLN power plant to hundreds of kilo Volts to be distributed, and then other transformers reduce the voltage to the voltage needed by every household and office that generally uses 220Volt AC Voltage.

The following is the shape dan symbl of trafo as figure 7
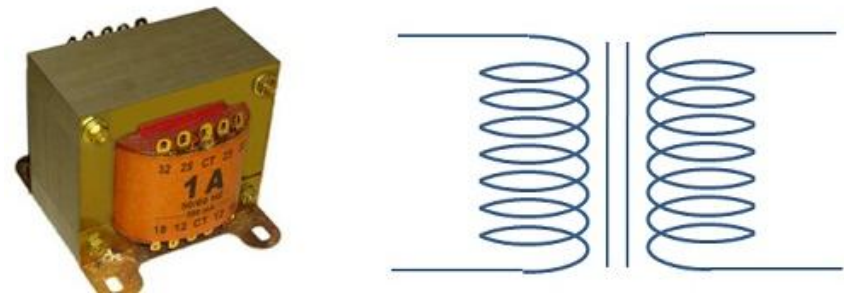

Fig. 7 Trafo Symbol and Shape

\subsection{IC Regulator}

The regulator is an IC that is used to stabilize the voltage so that the voltage is always in a constant condition. In the world of robotics, power is very important because many components, for example IC / $\mathrm{uC}$ or a series is very disturbed if the voltage supply is unstable. There are several types of IC regulators that can be seen more clearly in table 5 .

Table. 5 Type of IC Regulator

\begin{tabular}{c|l}
\hline Type & \multicolumn{1}{c}{ Function } \\
\hline 7805 & $\begin{array}{l}\text { Functions to decrease positive voltage above 5 } \\
\text { volt becomes 5 volt positive voltage. }\end{array}$ \\
7905 & $\begin{array}{l}\text { Functions to decrease negative voltage above 5 } \\
\text { volt becomes 5 volt positive voltage. }\end{array}$ \\
7809 & $\begin{array}{l}\text { Functions to decrease positive voltage above 9 } \\
\text { volt becomes 9 volt positive voltage. }\end{array}$ \\
7909 & $\begin{array}{l}\text { Functions to decrease negative voltage above 9 } \\
\text { volt becomes 9 volt negative voltage. }\end{array}$ \\
7812 & $\begin{array}{l}\text { Functions to decrease positive voltage above 12 } \\
\text { volt becomes 12 volt negative voltage. }\end{array}$ \\
7912 & Functions to decrease negative voltage above \\
& 12 volt becomes 12 volt negative voltage. \\
\hline
\end{tabular}

IC Regulator physical form as shown in figure 8 .

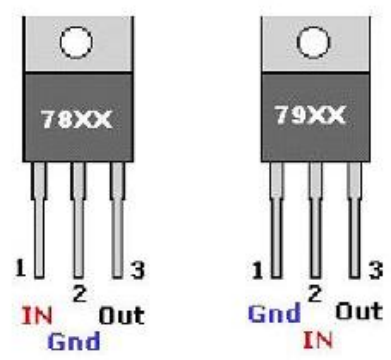

Fig. 8 IC Regulator

\subsection{Relay}

Relay is an output component that is most often used in some electronic equipment and in various other fields [11]. Relay serves to connect or disconnect the flow of electric current that is controlled by providing a certain voltage and current in the coil. There are two types of relay based on the voltage to drive the coil, namely AC and DC. There are various types of relay based on the pole. In the design this time used Single
Pole Double Throw (SPDT) and Double Pole Double Throw (DPDT) which serves to connect and disconnect the current to move equipment outside the circuit. Physical form of relay such as figure 9 .
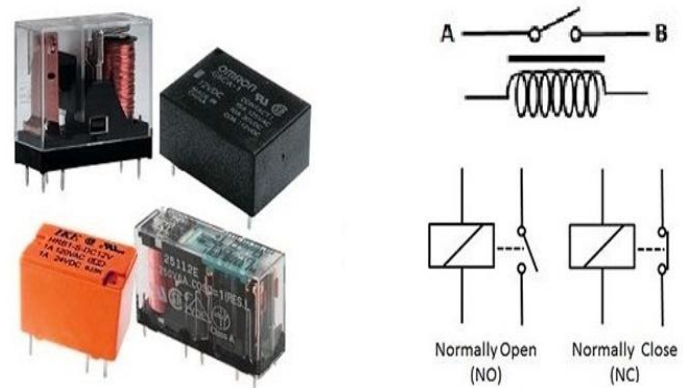

Fig. 9 Relay

\subsection{Resistor}

Resistor is an object that is made as an obstacle or restraint to the electric current that flows in a circuit with a voltage to regulate the flowing current which is expressed in ohm. Physical form of resistor is like figure 10.

\section{Resistors}
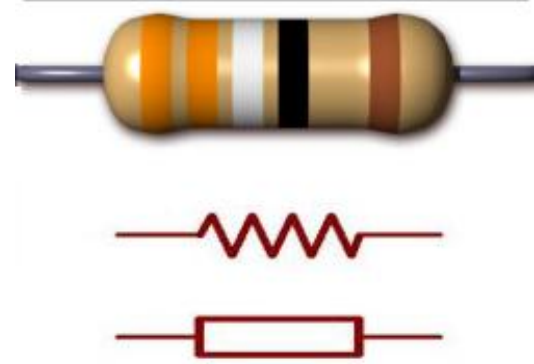

Fig. 10 Resistor

The following is colour table to determine the large of resistor as mentioned in table 6 .

Table. 6 Resistor Colour

\begin{tabular}{|l|c|c|c|c|c|}
\hline $\begin{array}{c}\text { Warna } \\
\text { Cincin }\end{array}$ & $\begin{array}{c}\text { Cincin } \\
\text { I }\end{array}$ & $\begin{array}{c}\text { Cincin } \\
\text { II }\end{array}$ & $\begin{array}{c}\text { Cincin } \\
\text { III }\end{array}$ & $\begin{array}{c}\text { Cincin IV } \\
\text { Pengali }\end{array}$ & $\begin{array}{c}\text { Cincin V } \\
\text { Toleransi }\end{array}$ \\
\hline Hitam & 0 & 0 & 0 & $\times 1$ & \\
\hline Coklat & 1 & 1 & 1 & $\times 10^{1}$ & $\pm 1 \%$ \\
\hline Merah & 2 & 2 & 2 & $\times 10^{2}$ & $\pm 2 \%$ \\
\hline Jingga & 3 & 3 & 3 & $\times 10^{3}$ & \\
\hline Kuning & 4 & 4 & 4 & $\times 10^{4}$ & \\
\hline Hijau & 5 & 5 & 5 & $\times 10^{5}$ & \\
\hline Biru & 6 & 6 & 6 & $\times 10^{5}$ & \\
\hline Ungu & 7 & 7 & 7 & $\times 10^{7}$ & \\
\hline Abu- abu & 8 & 8 & 8 & $\times 10^{5}$ & \\
\hline Putih & 9 & 9 & 9 & $\times 10^{9}$ & \\
\hline Emas & & & & $\times 0,1$ & $\pm 5 \%$ \\
\hline Perak & & & & $\times 0,01$ & $\pm 10 \%$ \\
\hline Tanpa warna & & & & & $\pm 20 \%$ \\
\hline
\end{tabular}

\subsection{Diode}

Diode is a semiconductor device that flows only one-way current. The diode is made of germanium or silicon known as a diode junction.

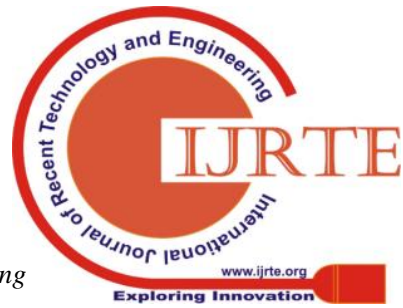


The structure of this diode, as the name implies, is the connection between $\mathrm{P}$ type semiconductor and $\mathrm{N}$ type semiconductor. $\mathrm{P}$ type semiconductor acts as anodes and type $\mathrm{n}$ semiconductor acts as cathode. With a structure like this, the current can only flow from the $\mathrm{P}$ side to the $\mathrm{N}$ side. Physical form of diode is like figure 11.

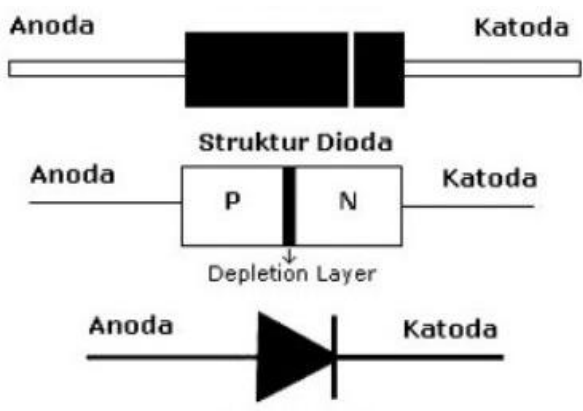

Fig. 11 Dioda

\subsection{Capacitor}

Capacitor is electronic component that functions to store electrical charges. The capacitor consists of two parallel metal pieces separated by an insulator called a dielectric. The shape of the capacitor is like figure 12 .

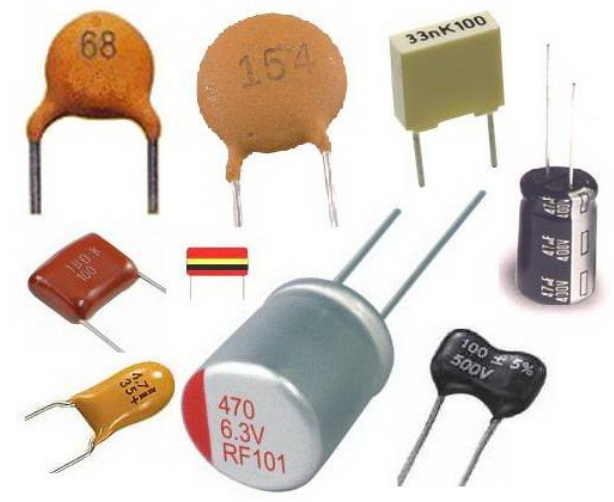

Fig. 12 Capacitor

\subsection{Buzzer}

Buzzer is a device that can convert electrical signals into sound signals. In general, the buzzer is used for alarm because the user is quite easy, that is by providing an input voltage, the buzzer will emit a sound. The frequency of the noise released by the buzzer is between 1-5 KHz.

Basically the working principle of the buzzer is almost the same as the loud speaker, so the buzzer also consists of an aygn coil mounted on the diaphragm and then the coil is flowed by current so that it becomes an electromagnet, the coil will be pulled in or out, depending on the direction of the current and polarity of the magnet, due to the coil mounted on the diaphragm, each coil movement will move the diaphragm back and forth so as to make the air vibrate which will produce a noise. Buzzer is usually used as an indicator that the process has been completed or an error occurs in a device (alarm). Physical form of buzzer as shown in figure 13.

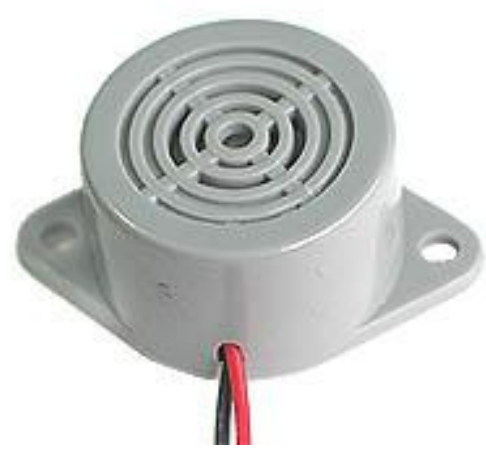

Fig. 13 Buzzer

\subsection{GSM (Global System Mobile) Module}

The GSM module is equipment designed to be used for communication applications from machine to machine or from human to machine. The GSM module is an equipment used as a machine in an application. In the application made there must be a microcontroller that will send command to the GSM module in the form of an AT command via RS232 as a communication component. There are several types of GSM Modules such as Wavecom Modem, 800L Sim, 900A Sim, etc. Form of an 800L GSM SIM Module as shown in figure 14

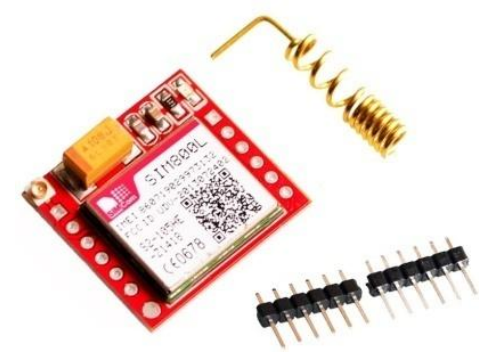

Fig. 14 GSM SIM 800L Module

The GSM module is part of the control center that functions as a transceiver. The GSM module has the same function as a cellular telephone that is capable of sending and receiving SMS. With the existence of a GSM module, the designed application can be controlled remotely by using the GSM network as an access media.

\subsection{Arduino Program (IDE)}

Arduino IDE Software is an open-source single-board micro controller, derived from the Wiring platform, designed to facilitate electronic use in various field, its hardware uses the Atmel AVR processor and its software has a simple $\mathrm{C}++$ programming language and its complete fun-loving functions. , so that Arduino is easy to learn by beginners. Figure 15 shows the initial appearance of the IDE Arduino software.

Arduino IDE is made from the JAVA programming language. The Arduino IDE also comes with a $\mathrm{C} / \mathrm{C}++$ library called Wiring which makes input and output operations become easier.

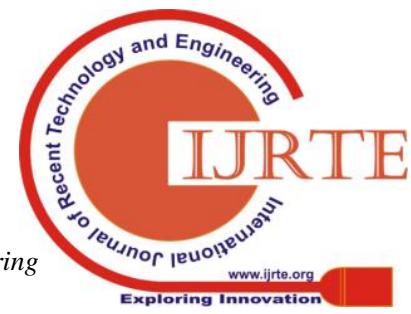


This Arduino IDE was developed from Processing software which was overhauled into an Arduino IDE specifically for programming with Arduino.

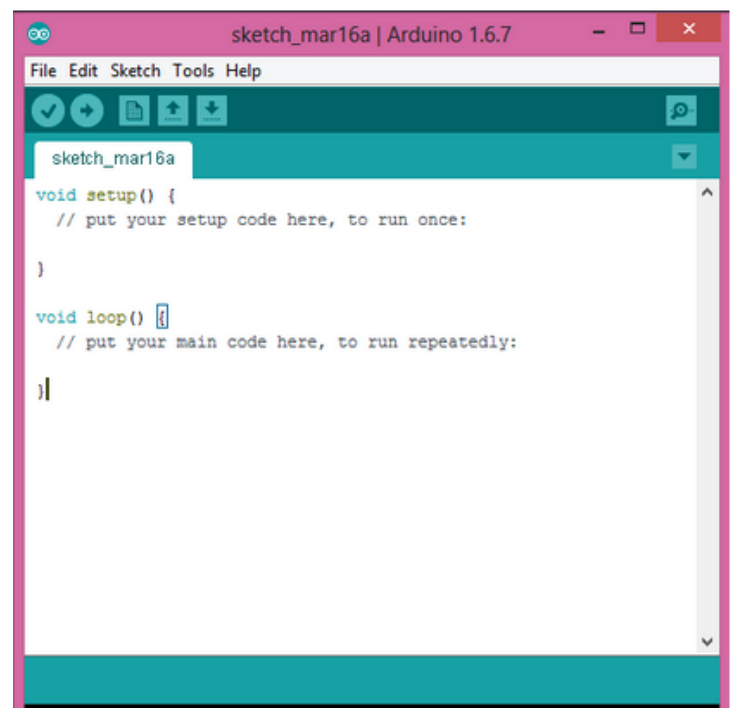

Fig. 15 Arduino (IDE) Program

\subsection{Arduino C-Based Programming Language}

The basic structure in Arduino programming consists of two parts, namely the preparation function (setup) and the main function (loop). The setup () function is used to define the variables used in the program, while the loop () is the core / main program of Arduino that is run continuously.

The following the main functions in Arduino C-Based Programming Language : setup()

1. Setup() function is called when the program run, functions as pin mode initialitation as input or output and serial intialitation. This function must be exista while there is

2. $\operatorname{loop}()$

Program in loop() function will be exectude contionusly.

1. Function

Function is a set of instruction block that have their own name and this instruction block will be executed when this function is called. The writing of this function must be preceded by the function type after that the function name and then the parameter, if there is no value generated from the function, the function type is void ().

2. \{\} (curly bracket)

That is used to start and to finish a function, instruction block like $\operatorname{loop}()$, void() and instruction for and if.

3. ; (semicolon)

Is used to be final sign of instruction

4. $/ * \ldots . . . * /$ (commentar block)

Is used in comments that have more than one row. Anything written in this comment block has no effect on the program created and will not waste memory.

5. // (row commentar)

Same as commentar block it is just only used for a row commentar.

6. Variable

Is an expression that is used to represent a value used in the program. A variable will hold the value according to the no instruction.

definition that has been made. Variable only need to be defined once but the value can match the program. There are two kinds of variables. There are global variables that can be used by all functions and instructions in the program. This variable is defined at the beginning of the program before the setup () function. And there are local variables where this variable is defined in a function or in a loop function. This variable can only be seen and be used in the function.

Types of data in variable :
a) Byte
b) Int
c) Long
d) Float
7. Array

Array is a collection of values accessed by an index number. Each value in an array can be called by calling the array name and number

\section{Arithmetic}

Arithmetic operator includes addition, subtraction, multiplication, and division

9. Joint operation

Is a combined mathematical operation that commonly used in program.

10. Comparison operator

Operator to compare 2 constants or variables that are often used to test a true or false condition.

11. Logical operator

Logical operator, $A N D, O R$, dan NOT is often used in if statement

\section{Constant}

Arduino language has set value, it is called constat. They are used to make the program easy to read

\section{TRUE / FALSE}

Is Boolean constant that defines logical score.

\section{HIGH / LOW}

This constant determines the pin value as HIGH or LOW and is used when reading or writing a digital pin. HIGH is defined as the logic level of 1 / ON / 5 Volt, while LOW is the logic level of 0 / OFF / 0 Volt.

\section{Input / Output}

Constans used in pinMode function, this constan is to determine digital pin mode as input or output.

16. If

Instruction for testing whether a condition has been reached or not, such as comparing the value of a variable above a certain amount, and executing each instruction in parentheses if the statement is true, otherwise it will be skipped.

17. if.....else

It allows to execute other instructions if a condition is not met. else can also be used more than one.

18. for

The for statement is used to repeat an instruction block in curly bracket.

\section{Published By:}


19. while

The while function will run the program continuously until a condition in the while function is wrong.

20. do.....while

The command to do something continuously to reach until it reaches a condition that does not meet the desired condition.

21. pinMode(pin, Mode)

The instruction used in the setup () has the function to initialize a pin as input or output.

22. digitalRead(pin)

The instructions used to read the input of a pin which results in the form of HIGH or LOW logic. A pin can be interpreted as a variable or constant $0-13$ that represents the input and output of the Arduino board.

23. digitalWrite(pin,value)

Instruction for providing HIGH (1) or LOW (0) output values on digital pins

24. analogRead(pin)

Instruction for reading analog input value with 10 bit resolution. This instruction only applies A0-A5 pins that are able to read analog values. Because the resolution is 10 bits, the digital readings are 0 to 1023 .

25. analogWrite(pin,value)

The instruction that works to give the PWM (pulse width modulation) value to the output. The arduino PWM pin is marked with tilde $(\sim)$, ie pins 3,5,6,9,10, and 11 .

26. $\operatorname{delay}(\mathrm{ms})$

Instructions for giving a break before proceeding to the next program.

\section{7. millis()}

Instruction for retrieving the time value since the program starts until the program stops or turned off

\section{8. tone(pin,frequency, duration)}

Instructions for producing frequency tunes with certain duration and sent to the intended pin.

\section{9. noTone(pin)}

Instruction to stop the frequency generated at the intended pin.

30. randomSeed(seed)

Instruction to take random score with the start seed score

31. $\operatorname{random}(\max )$; $\operatorname{random}(\min , \max )$

The random instruction $(\max )$ functions to take a random score with the max as the maximum score limit of the random () function. Random instruction ( $\min , \max$ ) functions to take arbitrary score between min and max score.

32. Serial.begin(rate)

Instructions for opening a serial data port for serial communication either send or receive data from the serial. Rate is the baud rate used for serial communication (commonly used 9600).

\section{Serial.print(data)}

Instruction used for sending data to serial port.

34. Serial.read()

Instruction for receving data from serial port.

35. Serial.available()

Is the instruction to detect whether receiving data from a serial port? When receiving data, it will produce a value $>0$.

\subsection{Flowchart}

Flowchart is an analytical technique that is used to explain aspects of the information system clearly, precisely and logically. Flowchart uses a series of standard symbol to describe transaction processing procedure used by a company, as well as outlining the data flow in a system.

There are some flowcharts that can be used namely :

\section{A. System Flowchart}

System flowchart is a chart that shows overall flow of work from the system. This chart describes the sequence of procedures in the system. System flowchart shows what is done in the system. The system flowchart is configured by using predefined symbols.

\section{B. Document Flowchart}

Document flowchart or Form flowchart or Paperwork flowchart is a flowchart that shows the flow of reports and forms including copies. This document flowchart uses the same symbols as those used in the system flow chart.

\section{Schematic Flowchart}

Schematic flowchart is a flow chart that is similar to a system flow chart, which is to configure procedures in the system. The difference is a schematic flow chart besides using symbols of the system flow chart, also using computer figures and other equipment used. The purpose of using these figures is to make it easier to explain the symbols of the flow chart to people who are still ordinary.

\section{Program Flowchart}

Flowchart program consists of two types, namely the logic flowchart program and detailed computer program flowchart (detailed computer flowchart program). The logic flowchart program is used to illustrate logically each step in a computer program. The logic of the program's flow chart is prepared by the system analyst [12-47].

\section{E. Process Flowchart}

Process flowchart is a flow chart that is widely used in industrial engineering. It is useful for system analysts to configure the process in a procedure.

Based on the explanation above, the writer can draw conclusions that the flowchart is a general illustration about a system that runs and functions as a communication aid and for documenting and presenting activities ranging from manual, semi-manual and computerized. 


\section{DESIGN}

\subsection{Block Diagram and Flowchart Designing}

\subsubsection{Block Diagram Designing}

Diagram block description :

1. RFID functions as security key of home door

2. Sensor functions to detect person through door vibration.

3. Arduino UNO R3 Atmega328 as system controller for all devices, beside that Arduino functions as data processor from RFID and sensor to activate LED, Selenoid Door Lock, Sim 800L and Buzzer.

4. LED functions as an indicator of correct or wrong Tag RFID using indicator

5. Buzzer as warning to person trying open the door forcibly.

6. Sim 800L functions as SMS sender to home owner handphone.

\subsubsection{Flowchart designing}

Flowchart of Door Security Device Design using RFID with a warning system in the Short Message Service is divided into two conditions which include the condition of the closed door and opened door tool system condition.

\section{2 Hardware Designing}

\subsubsection{Component Used}

Components used in making circuit is shown at table 7 .

Table. 7 The List of Component Used

\begin{tabular}{|c|c|c|}
\hline No & Component & Quantity \\
\hline 1 & UNO R3 Arduino (ATMega328) & 1 piece \\
\hline 2 & Vibration Sensor Module (SW-420) & 1 piece \\
\hline 3 & DC 5v Relay & 2 pieces \\
\hline 4 & LED & 6 pieces \\
\hline 5 & SIM 800L Module & 1 piece \\
\hline 6 & Buzzer & 1 piece \\
\hline 7 & Resistor & 6 pieces \\
\hline 8 & Capacitor & 6 pieces \\
\hline 9 & Transistor & 2 pieces \\
\hline 10 & Pin male female & Sufficiently \\
\hline 11 & Jumper cable & Sufficiently \\
\hline 12 & Electric cable & Sufficiently \\
\hline 13 & inc007 Diode & 6 pieces \\
\hline 14 & 1A Transformer & 1 piece \\
\hline 15 & Solenoid Door Lock 12v & 1 piece \\
\hline 16 & IC Regulator 7805 & 1 piece \\
\hline 17 & IC Regulator 7812 & 1 piece \\
\hline
\end{tabular}

\subsubsection{Tool and Material Used}

Beside using the Electronic Components above, surely it will use the equipment and also supporting materials in making the Layout circuit . Tools and materials used are shown in table 8 .

Table. 8 Tool and Material List in PCB Layout Creation

\begin{tabular}{lll}
\hline No & Tool and Material & Quantity \\
\hline 1 & Sticker Paper & 1 sheet \\
2 & Ruler & 1 piece \\
3 & Cutter & 1 piece \\
4 & Electric hand drill & 1 piece \\
5 & Soft sandpaper & 1 sheet \\
6 & Smooth PCB board & 1 piece \\
7 & Feritclorida & Sufficiently \\
8 & PCB Leg & 8 pieces \\
9 & Plus screwdriver & 1 piece \\
10 & Minus screwdriver & 1 piece \\
\hline
\end{tabular}

Installation and soldering of components must be carried out carefully so as not to damage the path on the PCB and the legs of the component. The tools and materials needed are shown in table 9 as follows

Table. 9 Tools and materials needed

\begin{tabular}{c|l|c}
\hline No & Component & Quantity \\
\hline 1 & Solder & 1 piece \\
2 & Vacuum lead & 1 piece \\
3 & Lead & 1 roll \\
4 & Cutting Pliers & 1 piece \\
5 & Pliers & 1 piece \\
6 & Pinset & 1 piece \\
7 & Jumper cable & Sufficiently \\
8 & Multimeter & 1 piece \\
\hline
\end{tabular}

\subsection{Circuit Scheme}

\subsubsection{Arduino UNO}

Arduino is a tool controller center that uses ATMega328 microcontroller as its core. The following is a display of the Arduino UNO shown in figure 16. 


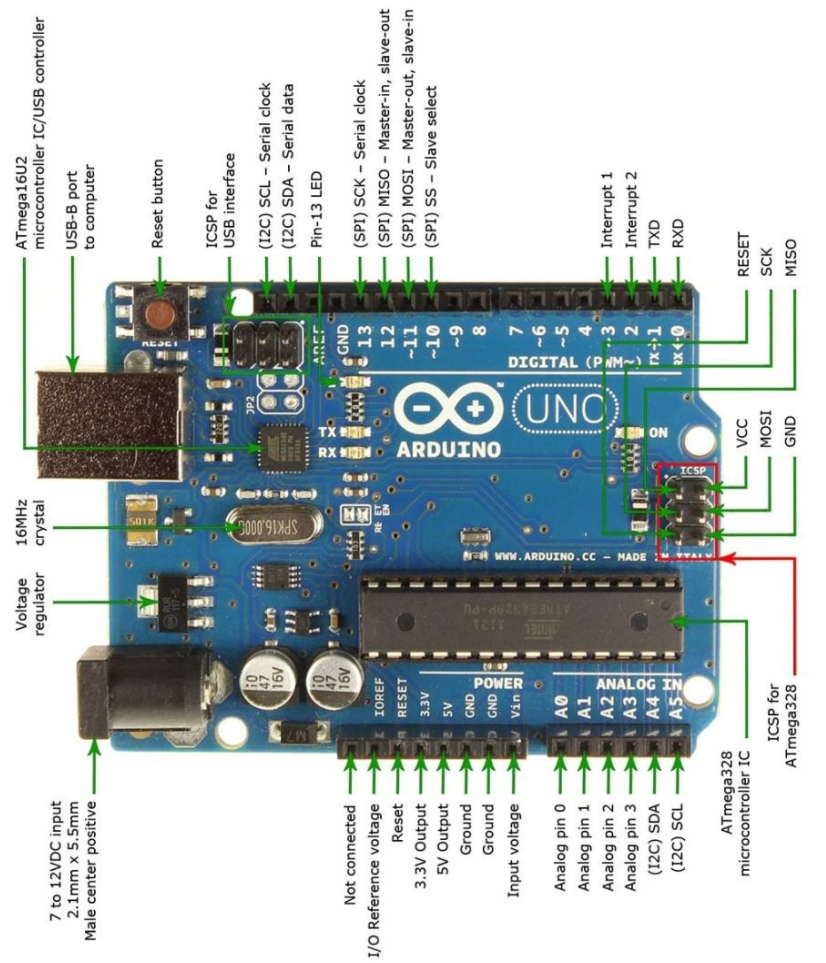

Fig. 16 Arduino UNO R3

\subsubsection{Relay Circuit}

Figure 17 and 18 below are scheme and layout of created relay circuit

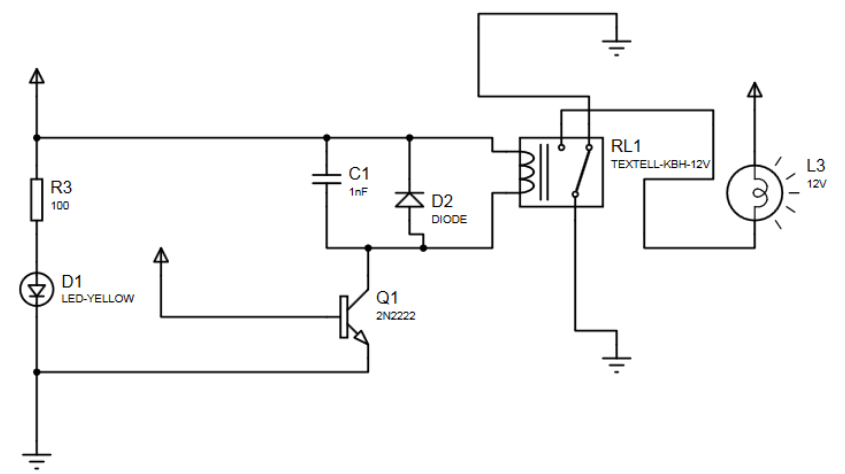

Fig. 17 Relay scheme circuit

Fig. 18 Relay Circuit Layout

\subsubsection{Power Supply Circuit}

Figure 19 and 20 are the scheme and layout of the power supply circuit consists of Ics regulator capacitors and diodes. The power supply source is an alternating AC source from PLN power plant.
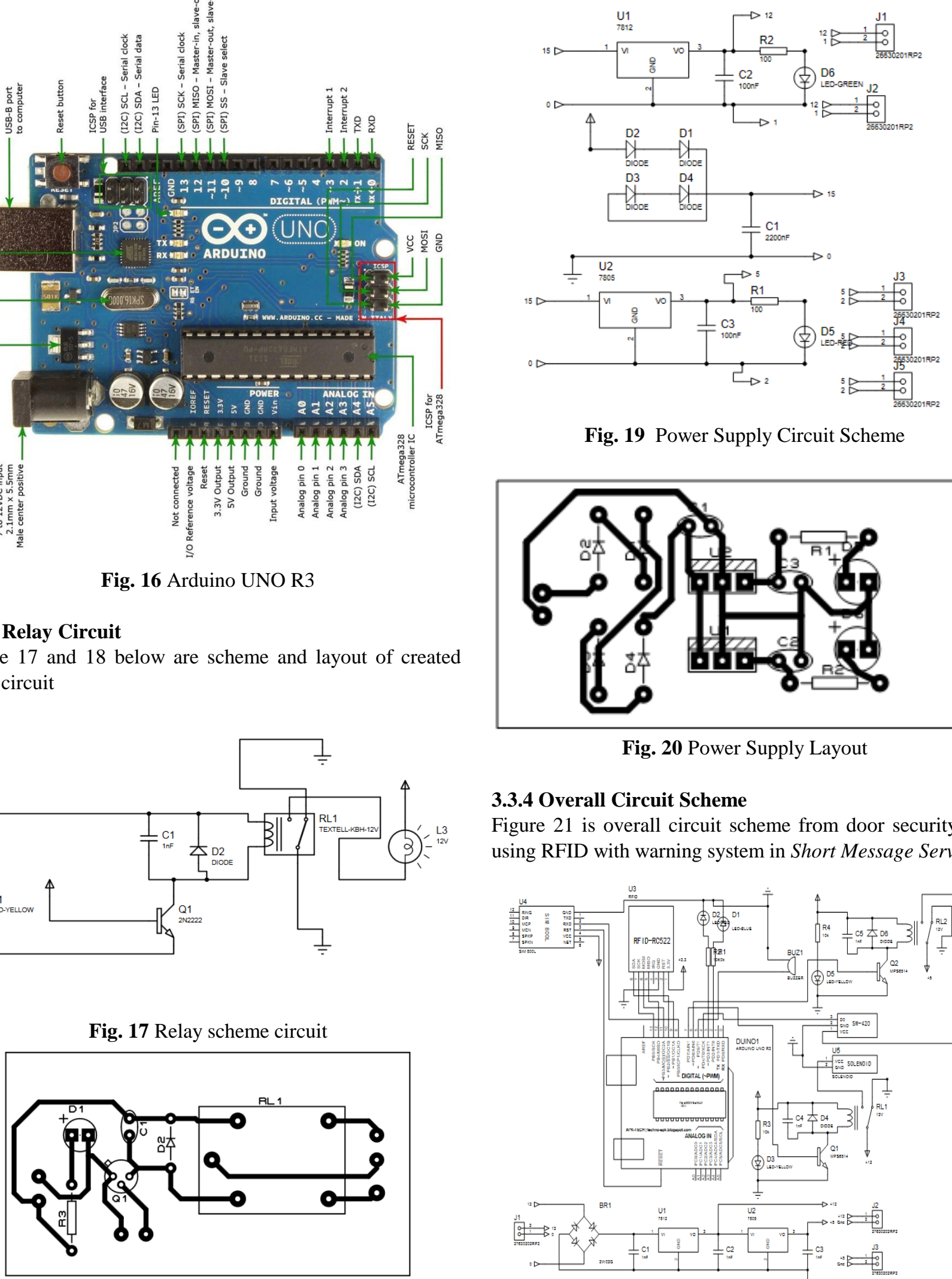

Fig. 19 Power Supply Circuit Scheme

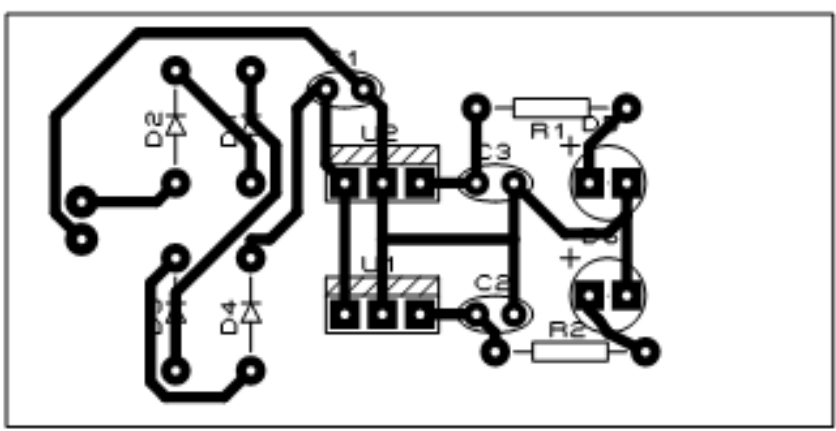

Fig. 20 Power Supply Layout

\subsubsection{Overall Circuit Scheme}

Figure 21 is overall circuit scheme from door security tool using RFID with warning system in Short Message Service

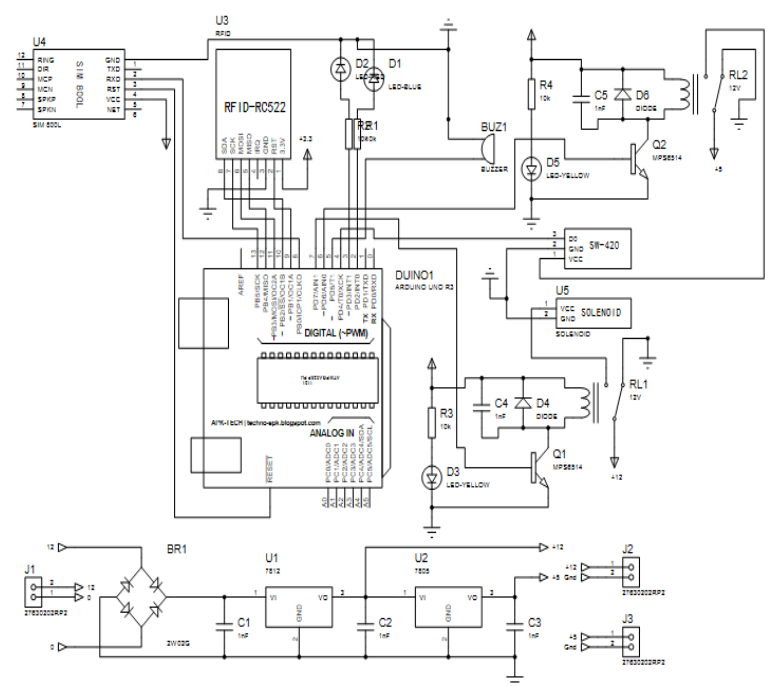

Fig. 21: Tool System Circuit

\subsection{Mechanic Desigining}

After completing the stages of designing hardware and software, then we can plan the creation of places to put the entire circuit that has been made.

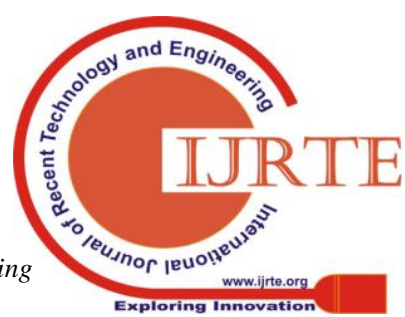


This stage is the most important part in Tool Design, because the success or failure of a tool or device creation is determined by the Circuit Design that we create, therefore in creating Design we must pay attention to the characteristics of each Component we use and we must also note that each component is connected to each other according to its function. When laying down the Component, this Mechanical Design must be in place because if the laying process is error it will generate not working instrument.

The box manufacturing planning process as a place for laying the Power Supply Circuit, Arduino, Relay and Tranfomator are as follows:

1. Make holes in the boxes that are already available. Arrange and install the circuit in the box regularly. Adjust the position of the circuit so that it does not appear to accumulate like figure 22 .
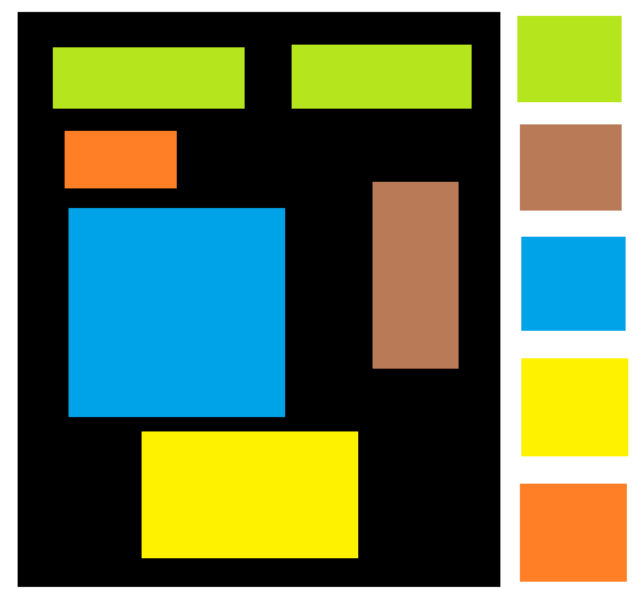

RELAY CATU DAYA ARDUINO TRANFORIMATOR

Fig. 22 Circuit Layout at the Box

2. Then arrange the RFID circuit, LED, and Vibration Sensor on the door, as in figure 23.

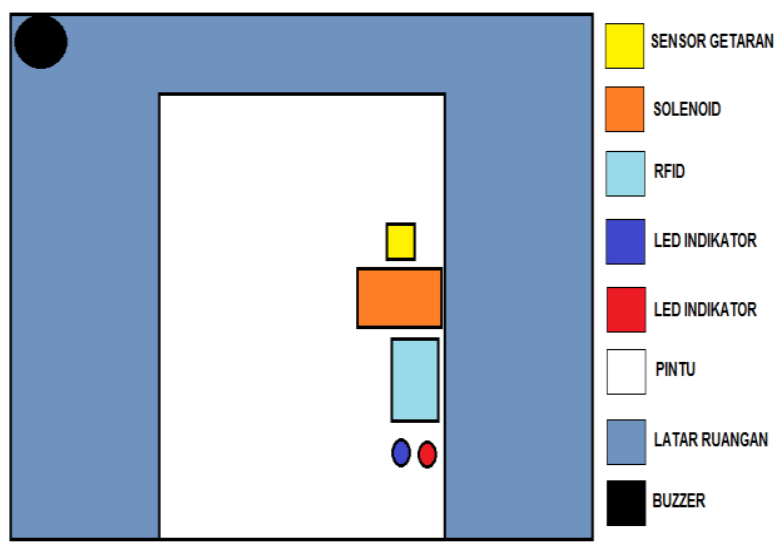

Fig. 23 Door security tool illustration

\subsection{Tool Working Way}

In the door security system that uses RFID and vibration sensor with this sms notification system all commands will be controlled by the Arduino Atmega 328 microcontroller. This door security system is equipped with RFID and vibration sensors as input and solenoid door lock, buzzer, and sms as output. The work system of the door security system tool consists of two conditions, the first condition is the locked door when the RFID tag id is brought close to the RFID reader located next to the door, the door lock solenoid valve will be attracted, the vibration sensor will turn off and the door can be opened, If the door is locked, that is the elongated door lock solenoid valve and the door receives sepiece vibration generated from the door of $30000 \mathrm{~Hz}$ which is read by the vibration sensor, the buzzer will be active and the microcontroller will command the sim 8001 module to send a message to the home owner and the second condition is the door when the RFID ID tag is brought close to the RFID reader which is next to the door, the door lock solenoid valve will elongate, the vibration sensor will turn on and the door will be locked.

\section{RESULT AND DISCUSSION}

\subsection{Tool Measurement and Testing}

After the design of the tool has been completed, to find out whether the assembly of the equipment is in accordance with the plan, it can be measured and tested to analyze the assembled equipment. The purpose of the measurement was to observe the voltage of the test points on a predetermined circuit block and find out how the circuit works, whether the circuit works according to plan and the more important with this measurement and testing is the writer can analyze and make conclusions about tool made.

\subsubsection{Measurement Steps}

As for the things to be considered when measuring a tool is the equipment used, the measurement point and the measurement results. The steps of this measurement are:

a. Check the equipment that will be used to ensure that the device is in good condition.

a. Determinate the circuit power and connect it to 220 volt voltage source.

b. Calibrate the multimeter first to measure so that it is obtained the accurate result.

c. Connect multimeter to testing point in the circuit

d. Record measurement result from every testing point.

e. After measuring, determinate all tools.

\subsection{Measurement Result}

\subsubsection{Measurement Result of IC Regulator Circuit}

The power supply circuit is the voltage source of this circuit. This power supply circuit consists of several components, one of which is the transformer as the input voltage source of the IC Regulator (7805 and 7812), the Regulator IC which functions as a voltage lowering which has a $5 \mathrm{~V}$ and $12 \mathrm{~V}$ output. In this circuit there are three points of reduction, namely TP1, TP2 and TP3. TP1 is the measurement point of input voltage in the IC Regulator, TP2 is the output voltage measurement point on IC 7805 and TP 3 is the output voltage at IC 7812. In table 10, it is the measurement result and in figure 24 is a description of the measurement test point. 


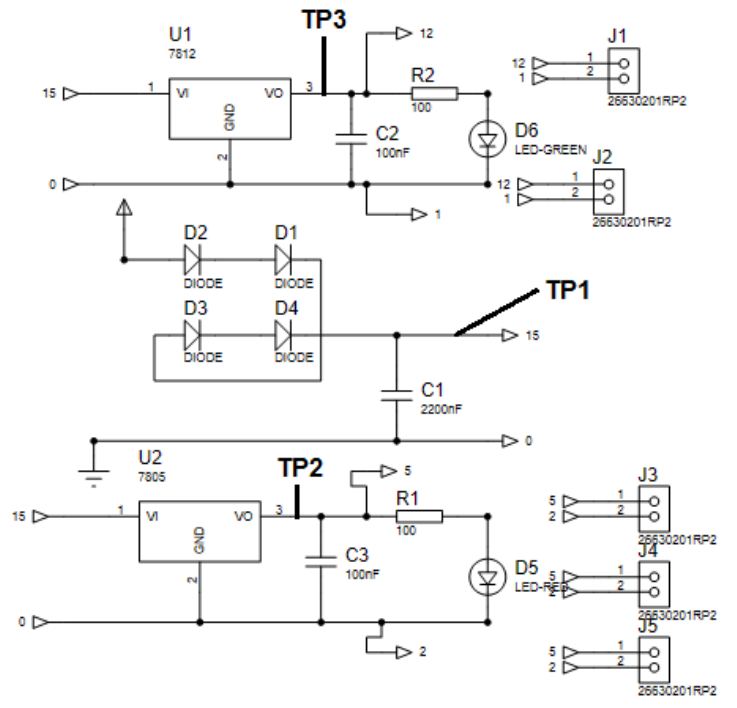

Table. 10 IC Regulator Voltage Measurement

\begin{tabular}{c|c|c|c}
\hline Measurement & TP1 & TP2 & TP3 \\
\hline 1 & 14,9 volt & 5,00 volt & 12,00 volt \\
2 & 15 volt & 5,00 volt & 12,00 volt \\
3 & 14,9 volt & 5,00 volt & 12,00 volt \\
\hline
\end{tabular}

\subsubsection{Measuremnt Result at Relay Circuit}

The Relay circuit is outage and working controller of the solenoid and vibration sensor. In this circuit there are two points of reduction, namely TP1 and TP2. TP1 is the input voltage measurement point for turning on the Relay circuit and TP2 is the input voltage measurement point to set the Normal Open (NO) in the Relay circuit. Table 11 is the measurement result and in figure 25 is a measurement test point.
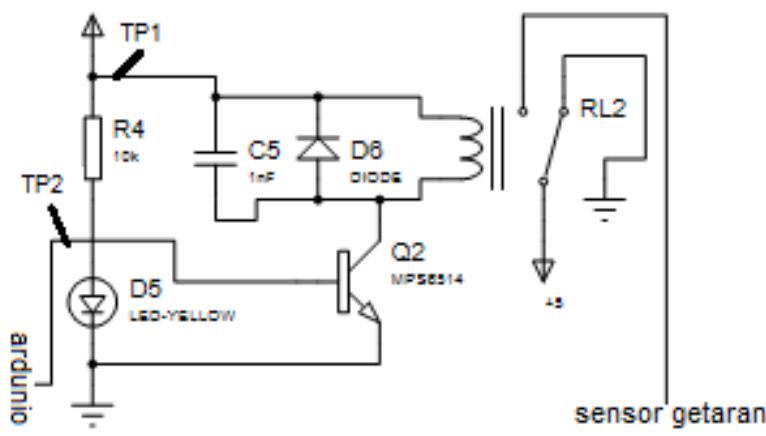

Fig. 25: Relay Circuit Measurement Point

Table. 11 The Results of Relay Circuit Measurement

\begin{tabular}{c|c|c}
\hline Measurement & TP1 & TP2 \\
\hline 1 & 5,00 volt & 4,9 volt \\
2 & 5,00 volt & 4,9 volt \\
3 & 5,00 volt & 4,9 volt \\
\hline
\end{tabular}

\subsubsection{The Measurement Result of Module SW-420}

\section{Circuit}

Module SW-420 circuit is a vibration sensor that reads vibrations in direct contact with the sensors used in this tool. In this circuit there are two points of reduction, namely TP1 and TP2. TP1 is the input voltage measurement point for
Fig. 24 Measurement Point in IC Regulator Point

turning on the SW-420 and TP2 series of modules which are the measurement points of the output voltage produced in the SW-420 module circuit. Table 12 is the measurement result and in figure 26 is a measurement test point.

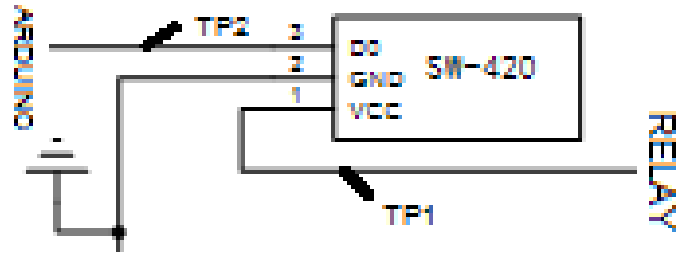

Fig. 26 Module SW-420 Circuit Measurement Point

Table. 12 Module SW-420 Circuit Measurement Result

\begin{tabular}{ccc}
\hline Measurement & TP1 & TP2 \\
\hline 1 & 5,00 volt & 4,7 volt \\
2 & 5,00 volt & 4,6 volt \\
3 & 5,00 volt & 4,7 volt \\
\hline
\end{tabular}

\subsection{Tool Testing Result}

In testing this tool, the researcher used the $20 \mathrm{~cm} \times 0 \mathrm{~cm}$ door and the computer to help get information of working way of the device with the Arduino IDE software. In testing this tool there are two conditions of the door, namely the condition of locked and opened door.

\subsubsection{Tool Testing at Looked Door}

In testing this tool to ease workflow of the tool analysis, Arduino is connected to the computer to display the work message tools. This test was carried out in two ways: attaching an RFID card to the RFID reader as a detector whether using an RFID card is correct or wrong, when the RFID card is used correctly it will appear on the computer as figure 27 which states that the RFID card is used correctly. Then when the RFID card is used incorrectly it will appear like figure 28 which express that the RFID card is wrong, and if the RFID reader detects an RFID card that is used incorrectly more than the same as 3 then it will send an SMS like figure 29 which shows wrong 3 times and figure 30 the contents of the SMS sent to the handphone.

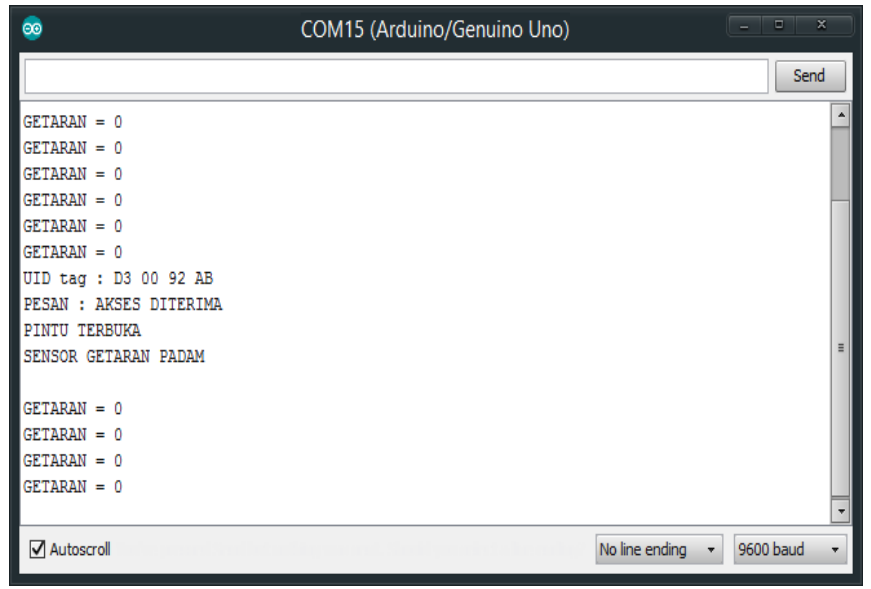

Fig. 27 Correct RFID Wrong 


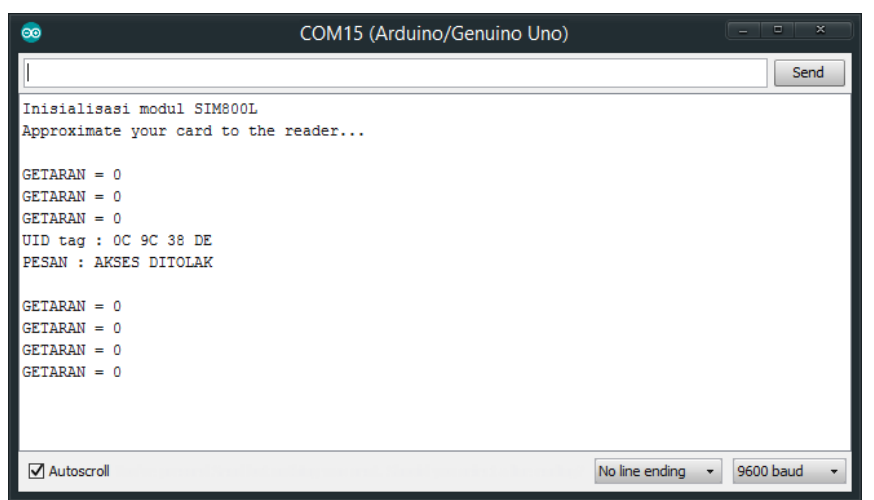

Fig. 28 Wrong RFID Card

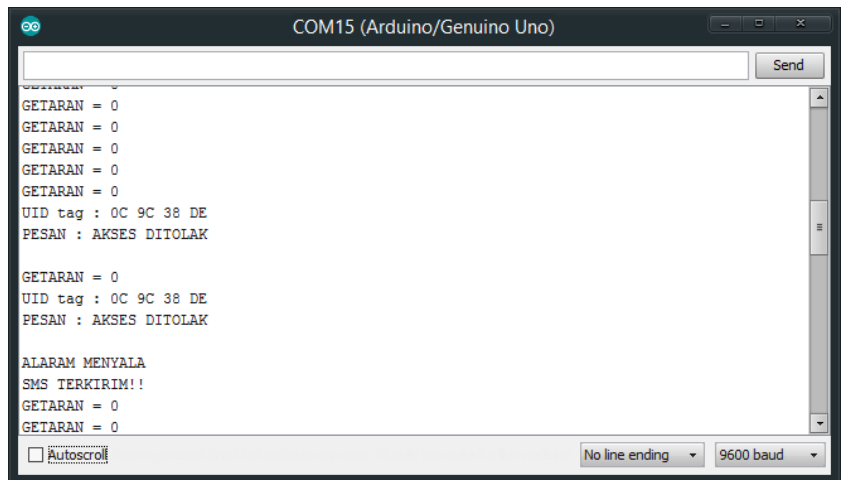

Fig. 29 Wrong RFID Card >= 3 and send SMS

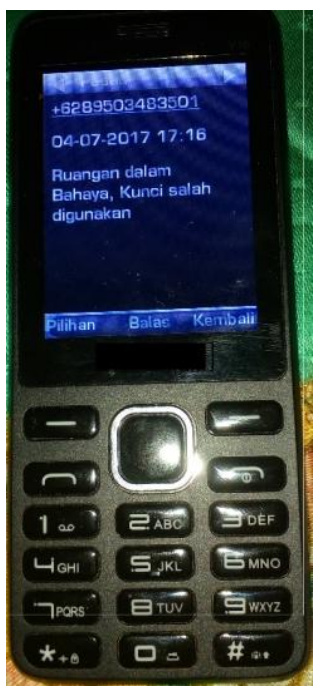

Fig. 30 Accepted SMS

In the second test that is detecting vibration on the door that would be expected to open the door forcibly. If the vibration sensor reads the vibration value $<30000 \mathrm{~Hz}$ then the door is normal or safe if the vibration value $>=30000 \mathrm{~Hz}$ then the door is opened forcibly or unsafe then it will turn on alarm and will send a notification to the homeowner via sms. In figure 31 shows the vibration value $<30000 \mathrm{~Hz}$ will be normal and vibration value $>30000 \mathrm{~Hz}$ the tool will send an SMS and in figure 32 the content SMS sent.

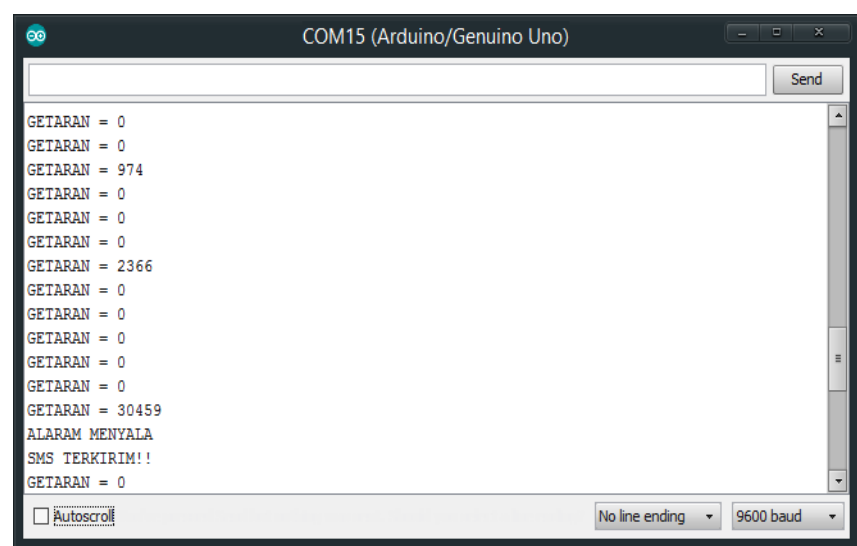

Fig. 31 Vibration value read

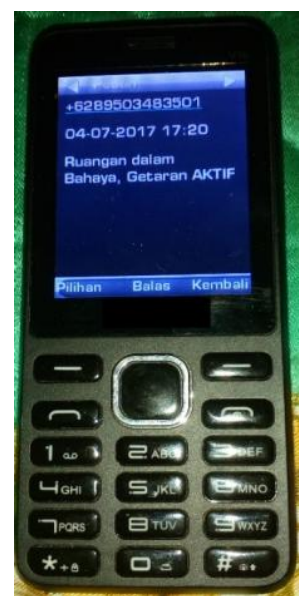

Fig. 32 SMS content sent

After testing this tool, it can be analyzed that the system will detect the RFID card used, correct or wrong, detect vibrations at the door and warn SMS and alarm when the door is in danger. In table 13 is a logic working tool table on RFID card detection and in table 14 is a logic working table on vibration detection on the door.

Table. 13 Working Tool Logic at Locked Door 1

\begin{tabular}{c|c|c|c|c|c}
\hline RFID & Condition & Door & SMS & Alarm & $\begin{array}{c}\text { Vibration } \\
\text { Sensor }\end{array}$ \\
\hline \multirow{2}{*}{ Detection } & Correct & Opened & $\begin{array}{c}\text { Not } \\
\text { sending } \\
\text { SMS } \\
\text { Not }\end{array}$ & $\begin{array}{l}\text { Not } \\
\text { Active }\end{array}$ & $\begin{array}{l}\text { Not } \\
\text { Active }\end{array}$ \\
& & & Not & \\
Detection & Wrong & Closed & sending \\
& & & SMS & Active & Active \\
Detection & Wrong $>$ & Closed & Sending \\
SMS & Active & Active \\
\hline
\end{tabular}

Table. 14 Working Tool Logic at Locked Door 2

\begin{tabular}{c|c|c|c}
\hline $\begin{array}{c}\text { Vibration } \\
\text { Sensor }\end{array}$ & $\begin{array}{c}\text { Vibration } \\
\text { Score }\end{array}$ & SMS & Alarm \\
\hline Detection & $<30000 \mathrm{~Hz}$ & $\begin{array}{c}\text { Not sending } \\
\text { SMS }\end{array}$ & $\begin{array}{c}\text { Not } \\
\text { active }\end{array}$ \\
Detection & $>30000 \mathrm{~Hz}$ & Sending SMS & Active
\end{tabular}

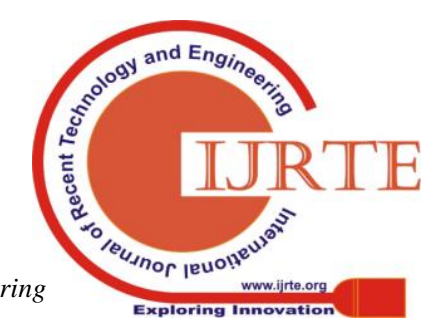




\subsubsection{Tool Testing at Opened Door}

This testing is done by attaching an RFID card to RFID reader as a detector to use the correct or wrong RFID card to lock the door. This tool can be analyzed that the system will detect an RFID card that is used correctly or incorrectly to wash the door and give an SMS alert and alarm to the homeowner if the door is estimated to be in danger. Table 15 shows the logic table working tool for detecting RFID card for washing the door.

Table. 15 Tool Working Logic at Opened Door

\begin{tabular}{|c|c|c|c|c|c|}
\hline RFID & $\begin{array}{l}\text { Cond } \\
\text { ition }\end{array}$ & Door & SMS & Alarm & $\begin{array}{l}\text { Vibration } \\
\text { Sensor }\end{array}$ \\
\hline Detection & Correct & Closed & $\begin{array}{l}\text { Not } \\
\text { Sending } \\
\text { SMS }\end{array}$ & $\begin{array}{l}\text { Not } \\
\text { Active }\end{array}$ & Active \\
\hline Detection & Wrong & Opened & $\begin{array}{l}\text { Not } \\
\text { Sending } \\
\text { SMS }\end{array}$ & $\begin{array}{l}\text { Not } \\
\text { Active }\end{array}$ & $\begin{array}{l}\text { Not } \\
\text { Active }\end{array}$ \\
\hline Detection & $\begin{array}{l}\text { Wrong } \\
>3\end{array}$ & Opened & $\begin{array}{l}\text { Sending } \\
\text { SMS }\end{array}$ & Active & $\begin{array}{l}\text { Not } \\
\text { Active }\end{array}$ \\
\hline
\end{tabular}

\subsection{Program Testing}

In this tool, use the $C$ programming language with Arduino IDE software. The following is an explanation of the program from the door security system to turn off RFID with SMS alert system as follows:

In the coding section, it gives the command to read vibration at the door and if the vibration measured more than $30000 \mathrm{~Hz}$ it will execute the alarm command active and send a message to the homeowner and if the vibration is below $30000 \mathrm{~Hz}$ then the door remains in normal condition.

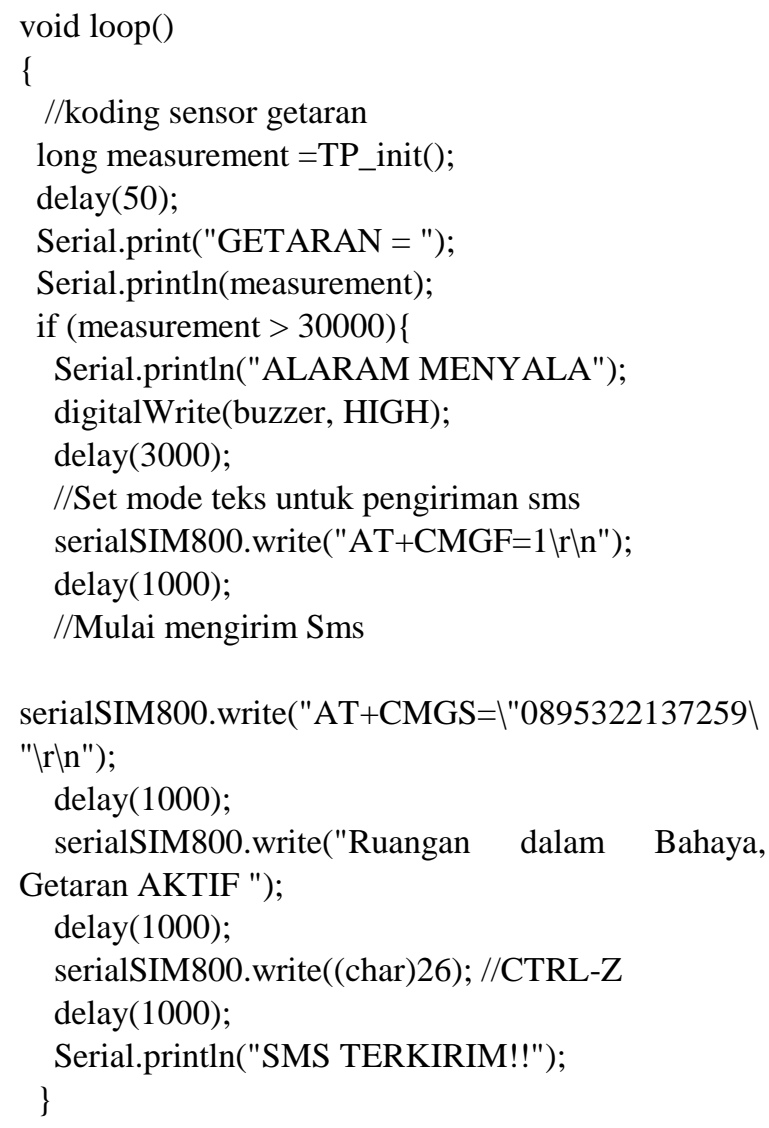

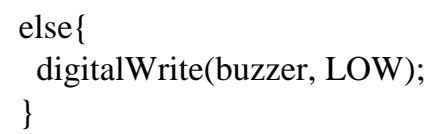

The coding below gives the command for the RFID reader to detect the RFID card, if the RFID card is correct then the command is executed as follows:

1. If the condition of the vibration sensor is on then it will be turned off, and vice versa, if the vibration sensor condition is toff then it will be turned on.

2. If the door is locked then the door will be opened, and if the door is opened, the door will be locked. The blue led indicator will be on.

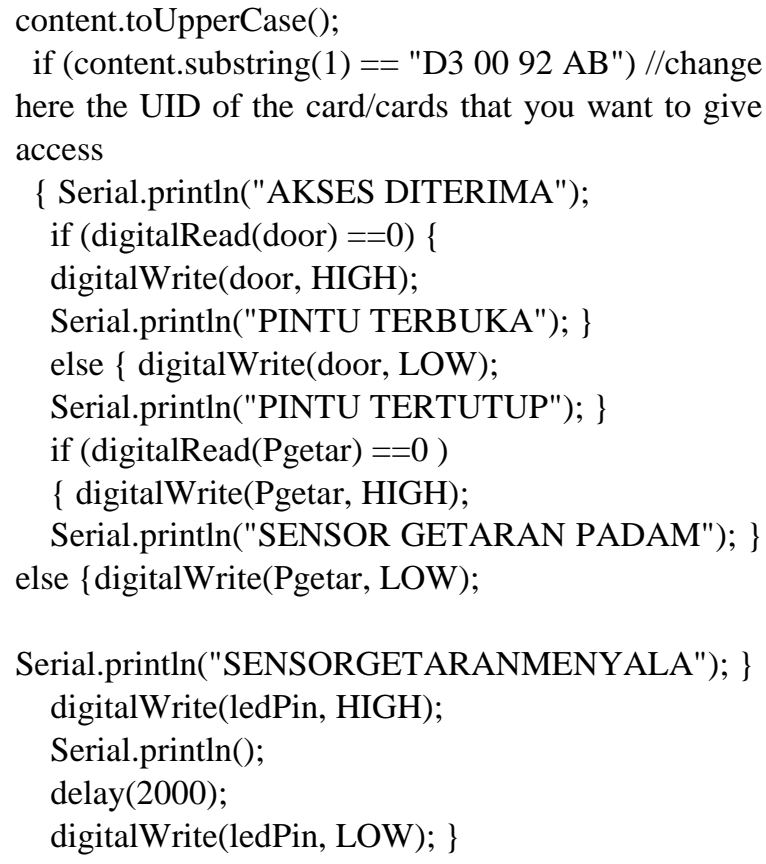

In the code below, if the RFID card is detected incorrectly, the red LED indicator will be on and if the RFID card is detected incorrectly more than the same as 3 times the alarm will live and send the SMS to the homeowner. Such as figure 30 and 31 , these are results of tool testing.

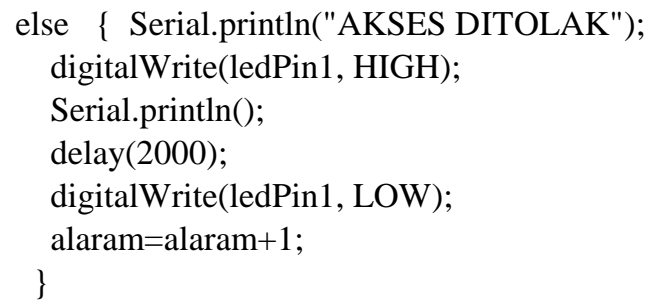


serialSIM800.write("AT+CMGS=|"0895322137259

"\rın");

delay(1000);

serialSIM800.write("Ruangan dalam Bahaya, Kunci

salah digunakan");

delay(1000);

serialSIM800.write((char)26); //CTRL-Z

delay(1000);

Serial.println("SMS TERKIRIM!!"); \}

\section{CONCLUSION AND SUGGESTION}

\subsection{Conclusion}

1. RFID is an identification to read data in Tag RFID that has different data.

2. SW-420 (Vibration sensor) is a sensor that reads vibration by direct contact. 3 .. If vibration $>30000 \mathrm{KHz}$ then the door is in the danger and arduino will give command to determinate the alarm and will send sms to the homeowner.

3. Arduino IDE software is used to give information about work tool.

\subsection{Suggestion}

1. Performing the development of sms that can open and close the door like RFID

2. Adding power supply stock to make the tool work although power outage.

\section{REFERENCES}

1. Miftakul Amin, M.; Maseleno, A.; Shankar, K.; Perumal, E.; Vidhyavathi, R.M.; Lakshmanaprabu, S.K. 2018. Active database system approach and rule based in the development of academic information system, International Journal of Engineering and Technology(UAE), v.7, n.2.26, pp. 95-101.

2. Miftakul Amin, M.; Sutrisman, A.D.I.; Stiawan, D.; Ermatita; Maseleno, A. 2018. Design restful web service of national population database for supporting e-health interoperability service, Journal of Theoretical and Applied Information Technology, v.96, n. 15, pp. 4797-4805.

3. Adole, P.; Mom, J.M.; Igwue, G.A. 2016. RFID Based Security Access Control System with GSM Technology, American Journal of Engineering Research (AJER), v. 5, n. 7, pp. 236-242.

4. Nwalozie, G.C.; Aniedu, A.N.; Nwokoye, C.S.; Abazuonu, I.E. 2015. Enhancing Home Security Using SMS-Based Intruder Detection System, International Journal of Computer Science and Mobile Computing, v.4, n.6, pp. 1177-1185.

5. Farooq, U.; Hasan, M.U.; Amar, M.; Hanif, A.; Asad, M.U. 2014. RFID Based Security and Access Control System, IACSIT International Journal of Egineering and Technology, v.6, n.4, pp. 309-314.

6. Miftakul Amin, M.; Azel Aji Nugratama, M.; Maseleno, A.; Huda, M.; Jasmi, K.A. 2018. Design of cigarette disposal blower and automatic freshner using MQ-5 sensor based on atmega 8535 microcontroller, International Journal of Engineering and Technology(UAE), v. 7, no. 3, pp. 1108-1113.

7. Kul, S.; Mudle, A.; Jivrak, V.; Dhamdhere, V. 2016. Arduino Based Security System, International Engineering Research Journal (IERJ), v. 2, n.2, pp. 671-674.

8. Gangi, R.R.; Gollapudi, S.S. 2013. Locker Opening and Closing System using RFID, Fingerprint, Password and GSM, International Journal of Emerging Trends \& Technology in Computer Science (IJETTCS), v.2, n.2, pp. 142-145.

9. Ajaykumar, M.; Kumar, N.B. 2013. Anti-Theft ATM Machine Using Vibration Detection Sensor, International Journal of Advanced

Research in Computer Science and Software Engineering, v.3, n.12, pp. 416-418.

10. Singh, G.; Singh, P.K.; Anshu; Chaudhary, B.; Thakur, G. 2016. Review on Digital Door Lock System, International Journal of Scientific Research and Management Studies (IJSRMS), v.3, n.4, pp. 170-174.

11. Widodo, S.; Amin, M.M.; Sutrisman, A. 2018. The Design of the Monitoring Tools of Clean Air Condition and Dangerous Gas CO, $\mathrm{CO} 2 \mathrm{CH} 4$ in Chemical Laboratory by Using Fuzzy Logic Based On Microcontroller. E3S Web of Conferences, ICENIS 2017, pp. 1-4.

12. Manikandan, V., et al. "PRIVACY PRESERVING DATA MINING USING THRESHOLD BASED FUZZY CMEANS CLUSTERING." ICTACT Journal on Soft Computing 9.1 (2018).

13. Batri, K., and M. Sivaram. "Testing the impact of odd and even point crossover of genetic algorithm over the data fusion in information retrieval." European Journal of Scientific Research (2012).

14. Steffin Abraham, Tana Luciya Joji , Sivaram M, D.Yuvaraj, "Enhancing Vehicle Safety With Drowsiness Detection Andcollision Avoidance" International Journal of Pure and Applied Mathematics, Volume 118 No. 22 2018, 921-927. https://acadpubl.eu/hub/2018-118 22/articles/22b/39.pdf

15. M. Sivaram, K. Batri, Amin Salih Mohammed and V. Porkodi, "Exploiting the Local Optima in Genetic Algorithm using Tabu Search", Indian Journal of Science and Technology, Vol 12(1), DOI: 10.17485/ijst/2018/v12i1/139577, January 2019.

16. Nithya, S., Sundara Vadivel, P., Yuvaraj, D., Sivaram, M. "Intelligent based IoT smart city on traffic control system using raspberry Pi and robust waste management", Journal of Advanced Research in Dynamical and Control Systems, Pages: 765-770, 2018.

17. Porkodi, V., et al. "Survey on White-Box Attacks and Solutions." Asian Journal of Computer Science and Technology 7.3 (2018): 28-32.

18. Viswanathan, M., Sivaram, M., Yuvaraj, D., Mohammed, A.S. "Security and privacy protection in cloud computing", Journal of Advanced Research in Dynamical and Control Systems, Pages 1704-1710, 2018

19. Mohammed, Amin Salih, D. Yuvaraj, M. Sivaram, and V. Porkodi. "Detection And Removal Of Black Hole Attack In Mobile Ad Hoc Networks Using Grp Protocol." International Journal of Advanced Research in Computer Science 10, no. 6 (2018).

20. Sivaram, M., B. DurgaDevi, and J. Anne Steffi. "Steganography of two LSB bits." International Journal of Communications and Engineering 1.1 (2012): 2231-2307.

21. Dhivakar, B., et al. "Statistical Score Calculation of Information Retrieval Systems using Data Fusion Technique." Computer Science and Engineering 2.5 (2012): 43-5.

22. K. Mahalakshmi, M.Sivaram, K. Shantha Kumari, D.Yuvaraj, R.Keerthika, "Healthcare Visible Light Communication", International Journal of Pure and Applied Mathematics, Volume 118 No. 112018 345-348, https://acadpubl.eu/jsi/2018-118-10-11/articles/11/41.pdf.

23. Punidha, R.,Pavithra K, Swathika R, and Sivaram M, " Preserving DDoS Attacks sing Node Blocking Algorithm.” International Journalof Pure and Applied Mathematics, Vol.119, o. 15, 2018, pp 633- 640 https://acadpubl.eu/hub/2018-119-15/3/473.pdf

24. Sivaram.M, Yuvaraj.D, Amin Salih Mohammed, Porkodi.V "Estimating the Secret Message in the Digital Image" International Journal of Computer Applications, 181(36):26-28, January 2019.

25. Punidha, R., avithra K, Swathika R, and Sivaram M, “Preserving DDoS Attacks sing Node Blocking Algorithm." International Journalof Pure and Applied Mathematics, Vol.119, o. 15, 2018, pp 633-640. https://acadpubl.eu/hub/2018-119-15/3/473.pdf

26. Sivaram, M., Yuvaraj, D., Porkodi, V., Manikandan, V. "Emergent news event detection from facebook using clustering" Journal of Advanced Research in Dynamical and Control Systems, Pages:1941-1947, 2018

27. Sivaram M, Batri K, “ Odd and Even Point Crossover Based Tabu GA for Data Fusion in InformationRetrieval",http://hdl.handle.net/10603/389 10-Apr-2015.

28. Sivaram, M. "Odd And Even Point Crossover Based Tabu Ga For Data Fusion In Information Retrieval." (2014)

\section{Published By:}


29. Malathi, N., and M.Sivaram. "An Enhanced Scheme to Pinpoint Malicious Behavior of Nodes In Manet's." (2015).

30. Mohammed, A.S., Kareem, S.W., Al Azzawi, A.K., Sivaram, M. "Time series prediction using SRE-NAR and SRE-ADALINE", Journal of Advanced Research in Dynamical and Control Systems, Pages: 1716-1726, 2018.

31. Mohammed, Sivaram Yuvaraj Amin Salih, and V. Porkodi. "Estimating the Secret Message in the Digital Image." International Journal of Computer Applications 181.36 (2019): 26-28

32. Sivaram, M., et al. "Estimating the Secret Message in the Digital Image." International Journal of Computer Applications 975: 8887.

33. Sivaram, M., et al. "The Real Problem Through a Selection Making an Algorithm that Minimizes the Computational Complexity."

34. Obulatha-II-ME-CSE, Miss O. "Position Privacy Using LocX."

35. SRE-NAR, Time Series Prediction Using. "SRE-ADALINE."

36. Kousik, N. V., M. Sivaram, and S. Kalidass. "AUTONOMOUS GREEDY ROUTING IN WIRELESS SENSOR NETWORKS."

37. S, Deepa and M, Sivaram, Enabling Anonymous Endorsement in Clouds with Decentralized Access Control (June 2015). International Journal of Scientific Engineering and Applied Science (IJSEAS) Volume-1, Issue-3, June 2015. Available at SSRN: https://ssrn.com/abstract $=3352128$

38. M, Sivaram, 4G and 5G Communication Networks Future Analysis (April 11, 2019). Available at SSRN: https://ssrn.com/abstract=

39. M, Sivaram and Sivaram, Porkodi and manikandan, V, Securing the Sensor Networks Along With Secured Routing Protocols for Data Transfer in Wireless Sensor Networks (OCTOBER 28, 2018). Available at SSRN: https://ssrn.com/abstract=

40. Sivaram, M., et al. "DETECTION OF ACCURATE FACIAL DETECTION USING HYBRID DEEP CONVOLUTIONAL RECURRENT NEURAL NETWORK." ICTACT Journal on Soft Computing 9.2 (2019)

41. R.Punidha, M.Sivaram, "Integer Wavelet Transform Based Approach For High Robustness Of Audio Signal Transmission", International Journal of Pure and Applied Mathematics, Volume 116 No. 232017 , 295-304, https://acadpubl.eu/jsi/2017-116-23-24/articles/23/40.pdf

42. Sivaram M., Mohammed A.S., Yuvaraj D., Porkodi V., Manikandan V., Yuvaraj N. (2019) Advanced Expert System Using Particle Swarm Optimization Based Adaptive Network Based Fuzzy Inference System to Diagnose the Physical Constitution of Human Body. In: Somani A., Ramakrishna S., Chaudhary A., Choudhary C., Agarwal B. (eds) Emerging Technologies in Computer Engineering: Microservices in Big Data Analytics. ICETCE 2019. Communications in Computer and Information Science, vol 985. Springer, Singapore

43. Sivaram M. et al. (2019) Expert System in Determining the Quality of Superior Gourami Seed Using Forward Chaining-Based Websites. In: Somani A., Ramakrishna S., Chaudhary A., Choudhary C., Agarwal B. (eds) Emerging Technologies in Computer Engineering: Microservices in Big Data Analytics. ICETCE 2019. Communications in Computer and Information Science, vol 985. Springer, Singapore

44. Amin Salih Mohammed et al., "Analysis of Mobile IP Wireless Networks in 5G International", Journal of Advanced Trends in Computer Science and Engineering, 8(1.2), 2019, 39- 42

45. S. Jeya Shobana et al., "FCCP - NS: A Fair Congestion Control Protocol with N-Sinks in Wireless Sensor Networks", International Journal of Advanced Trends in Computer Science and Engineering, 8(1.2), 2019, 43- 51

46. Sivaram, M., et al. "Retransmission DBTMA Protocol with Fast Retransmission Strategy to Improve the Performance of MANETs." IEEE Access (2019).

47. Yuvaraj D, Sivaram M, Karthikeyan B, and Jihan Abdulazeez, "Shape, Color and Texture Based CBIR System Using Fuzzy Logic Classifier" CMC, vol.59, no.3, pp.729-739, 2019. 